\title{
Perspectives on the leadership styles of West Virginia University Extension Service county program coordinators
}

\author{
Elaine Bowen \\ West Virginia University
}

Follow this and additional works at: https://researchrepository.wvu.edu/etd

\section{Recommended Citation}

Bowen, Elaine, "Perspectives on the leadership styles of West Virginia University Extension Service county program coordinators" (2004). Graduate Theses, Dissertations, and Problem Reports. 2551.

https://researchrepository.wvu.edu/etd/2551

This Dissertation is protected by copyright and/or related rights. It has been brought to you by the The Research Repository @ WVU with permission from the rights-holder(s). You are free to use this Dissertation in any way that is permitted by the copyright and related rights legislation that applies to your use. For other uses you must obtain permission from the rights-holder(s) directly, unless additional rights are indicated by a Creative Commons license in the record and/ or on the work itself. This Dissertation has been accepted for inclusion in WVU Graduate Theses, Dissertations, and Problem Reports collection by an authorized administrator of The Research Repository @ WVU.

For more information, please contact researchrepository@mail.wvu.edu. 
Perspectives on the Leadership Styles of West Virginia University Extension Service County Program Coordinators

\title{
Elaine Bowen
}

\author{
Dissertation submitted to the \\ College of Human Resources and Education \\ at West Virginia University \\ in partial fulfillment of the requirements \\ for the degree of
}

Doctor of Education

in

Educational Leadership Studies
Richard Hartnett, Ed.D., Chair
Cindy Fitch, Ph.D., R.D.
Ernest Goeres, Ph.D.
Helen M. Hazi, Ph.D.
Larry LeFlore, Ph.D.

Department of Advanced Educational Studies

Morgantown, West Virginia 2004

Keywords: Leadership, Extension Service, Educational Administration Copyright 2004 Elaine Bowen 


\section{ABSTRACT \\ Perspectives on the Leadership Styles of West Virginia University Extension Service County Program Coordinators}

\section{Elaine Bowen}

This research study examined the leadership styles of West Virginia University Extension Service County Program Coordinators from two perspectives. A sample of coordinators $(n=33)$ completed Bolman and Deal's Leadership Orientations (Self) Survey and Extension Service Committee members $(n=152)$ completed a Leadership Orientations (Other) Survey. Descriptive procedures, Pearson's product-moment correlation coefficients, and qualitative techniques were used to analyze the data.

Survey scores for the structural, human resource, political, and symbolic leadership frames were categorized into four leadership styles. Findings revealed the majority of coordinators (39\%) reported none of the four leadership frames were used frequently. The single frame style was the next most frequently used style (33\%), followed by paired frame style $(15 \%)$, and multiple frame style (12\%). Nearly three-fourths of the coordinators had a no frame style or a single frame style. Analysis of demographic variables indicated a significant relationship existed between program center assignment and frame style. Coordinators' self-rated leadership styles were compared with mean ratings from their County Extension Service Committee members. Committee members perceived coordinators to use a multiple frame style more frequently than coordinators perceived that they used. The majority of committee members reported a multiple frame style (55\%), no frame style (21\%), single frame style $(18 \%)$, and paired frame style $(6 \%)$. Eight of the 33 (24\%) coordinator-committee member matched scores agreed on the leadership style; twenty-five $(76 \%)$ of the matched scores did not agree. Coordinators with self-rated multiple frame styles were significantly more likely to also be perceived by committee members as a multiple frame style leader. Coordinators' surveys included open-ended questions on accomplishments, challenges, leadership skills, and behaviors. Office relationships, supervisory authority, budget issues, and lack of funding were common response themes.

This study has implications for extension organizations. Leaders at every level need to possess and frequently use structural, human resource, political, and symbolic leadership frame skills. Extension organizations need to understand leadership perceptions and strengthen competencies in order to deal effectively with today's leadership challenges and maximize leadership capacity. 


\section{DEDICATION}

I dedicate this effort to my family, the source of my inspiration, strength, and persistence Patrick, Wright, Austin, Louisa, and Everett. 


\section{ACKNOWLEDGEMENTS}

I am appreciative of the support and encouragement I've received throughout the journey of my doctoral program and dissertation. I extend my genuine thanks:

To county extension faculty for their participation in the study and their commitment as community and organizational leaders;

To the faculty and staff who routinely encouraged me through their caring attitude and helpfulness.

To WVU Extension Service administrative leaders (past and current) who provided opportunities to learn and challenge myself to be an effective leader.

To Dr. Richard Hartnett, my committee chair, for being both understanding and tough.

To Dr. Larry LeFlore for instilling confidence and backing me every step of the way.

To Dr. Cindy Fitch for constant encouragement and friendship.

To Dr. Ernie Goeres for his practical advice and occasional "How ya doing, kiddo?"

To Dr. Helen Hazi for her guidance in the final document preparation and her positive encouragement.

To Dr. Dick Walls for hours of patient guidance as I prepared the study methodology and data analysis.

To my parents, James and Mary Plazak, and siblings, Dave Plazak, Dan Plazak, Kathy Plazak, Mary Ellen Creasy, Marti Wade, and Jim Plazak, for creating a nurturing atmosphere for continuous learning and achievement.

To my children, Wright, Austin, Louisa, and Everett, for being understanding and doing extra tasks to help along the way.

Last but most importantly, to my husband, Pat, for constant and loving support. 
Table of Contents

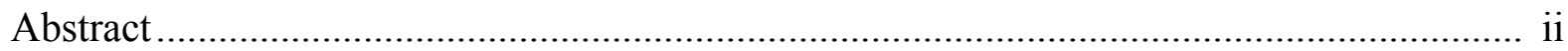

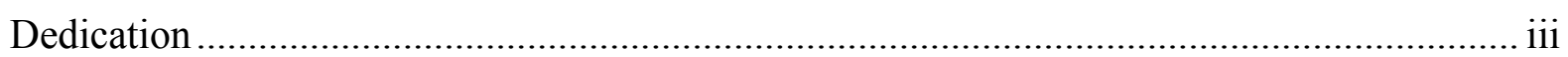

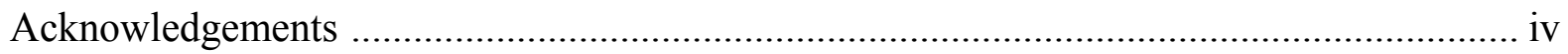

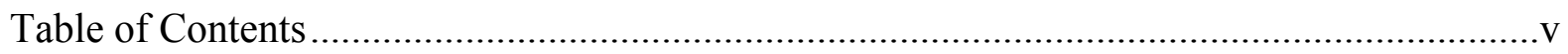

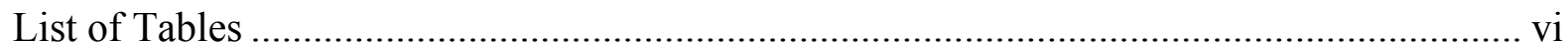

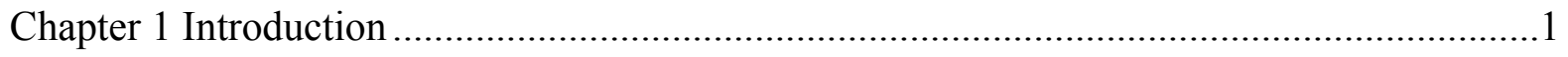

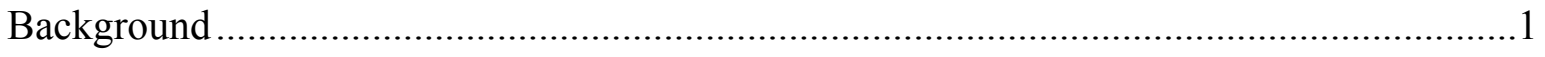

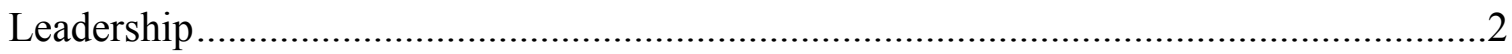

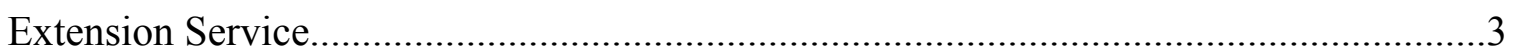

West Virginia University Extension Service - Leadership ........................................

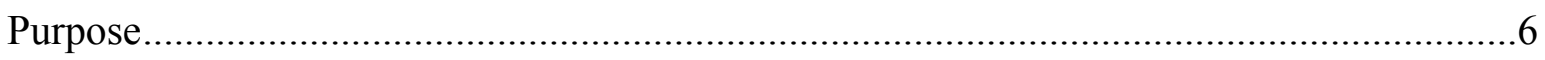

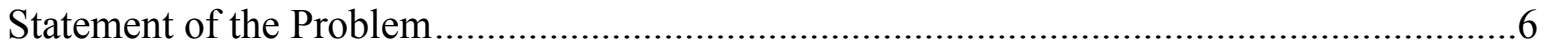

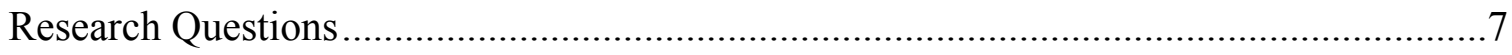

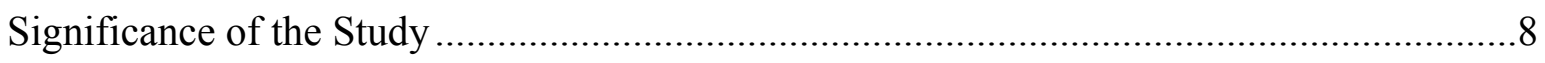

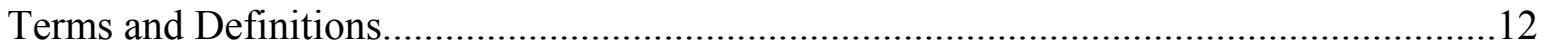

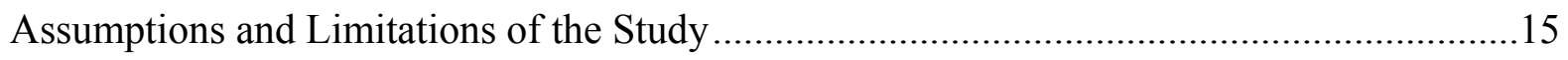

Chapter 2 Review of Related Literature ..................................................................... 18

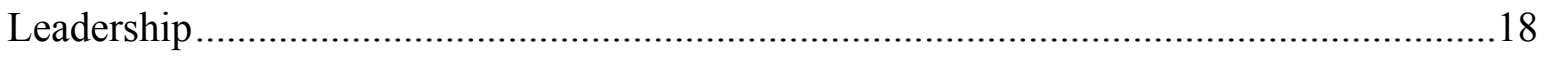

Bolman \& Deal Multi-Frame Leadership Model....................................................... 18

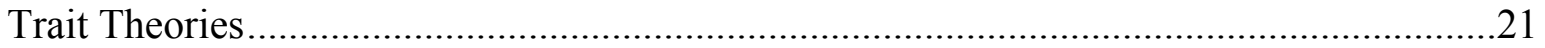

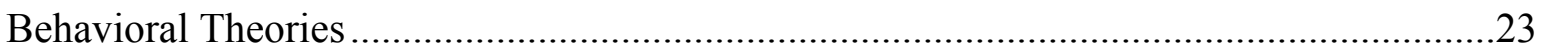

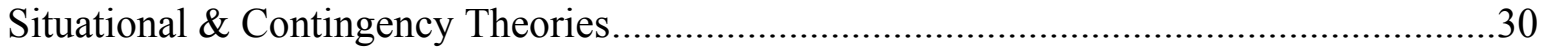




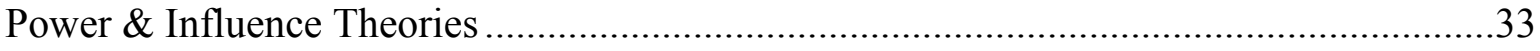

Research on the Four Leadership Frames ..................................................................39

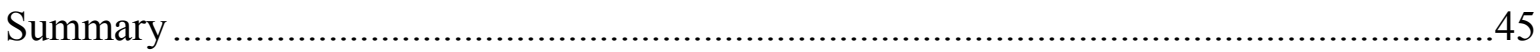

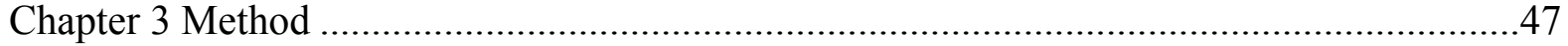

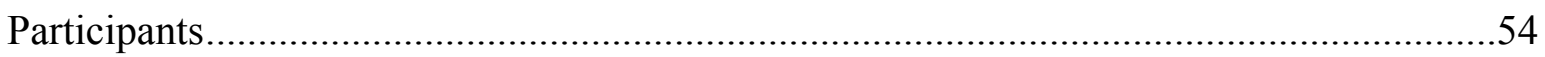

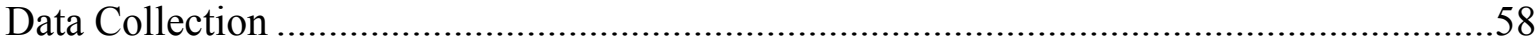

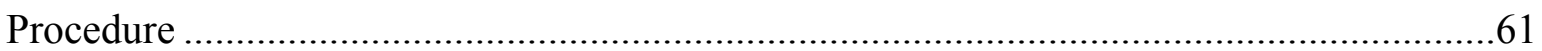

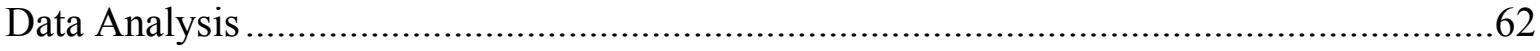

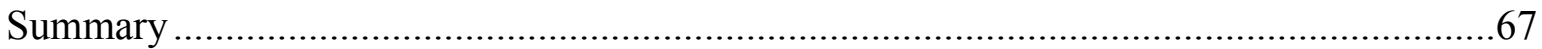

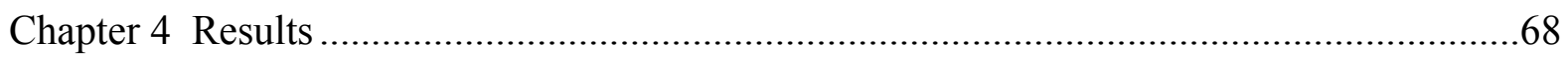

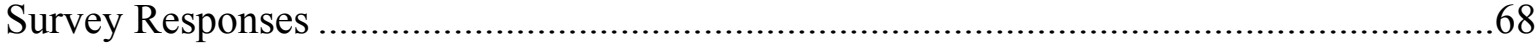

County Program Coordinator Data ........................................................................... 70

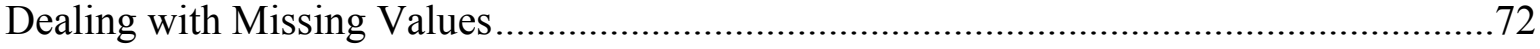

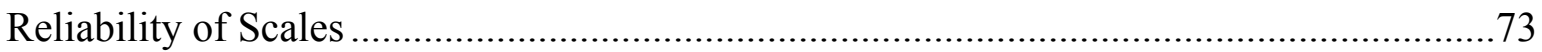

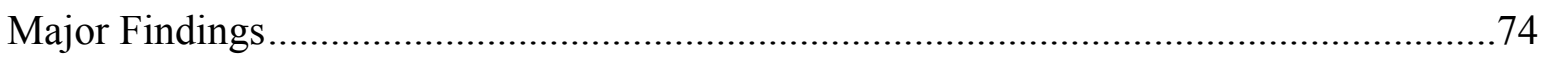

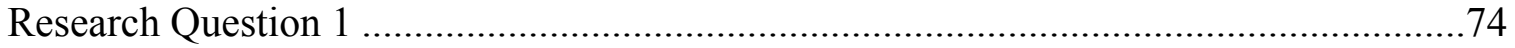

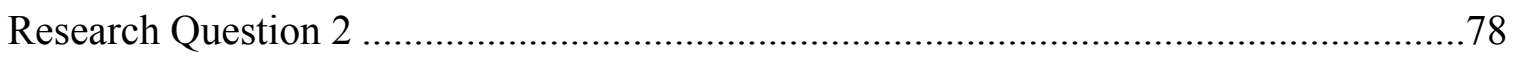

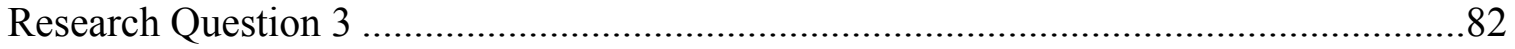

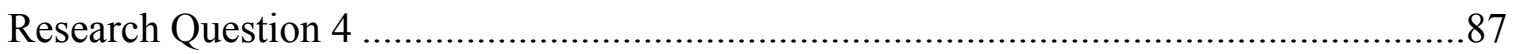

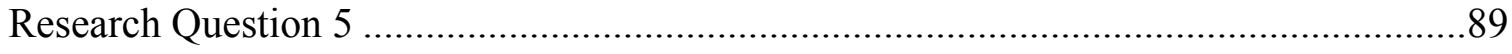

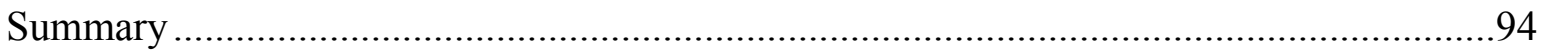

Chapter 5 Conclusions and Recommendations.......................................................98

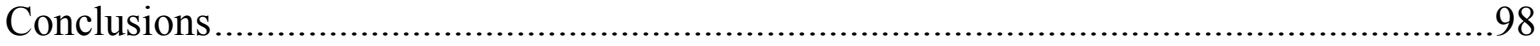


Leadership Styles of County Program Coordinators ........................................................98

Relationships Between Leadership Styles and Background Characteristics ...................101

Perspectives of Extension Service Committee Members ...................................................102

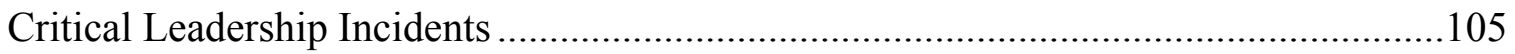

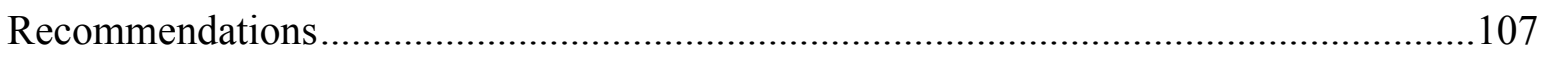

Recommendations for Leadership Practices ..................................................................107

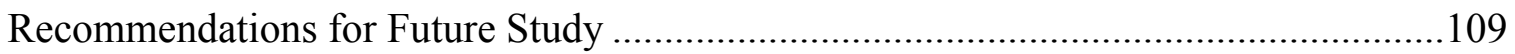

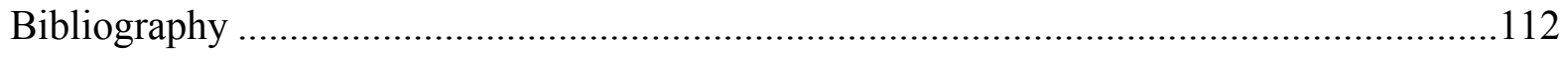

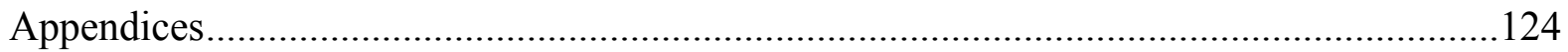

A. Permission to Use Survey …………………………...........................................124

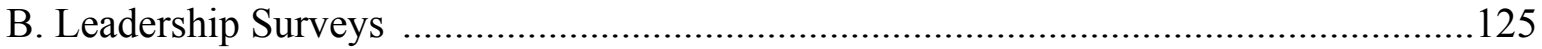

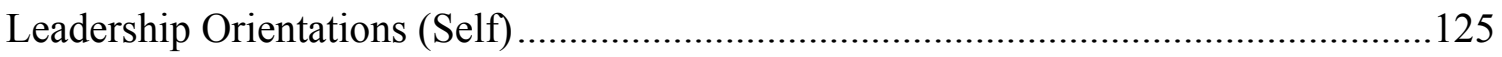

Leadership Orientations (Other) ............................................................................129

C. E-Mail Pre-notice to County Program Coordinators......................................................132

D. Pre-notice Letter to County Extension Service Committee Members.............................133

E. E-Mail Cover Letter to Selected County Program Coordinators ...................................134

F. Cover Letter to Selected County Extension Service Committee Members.....................135

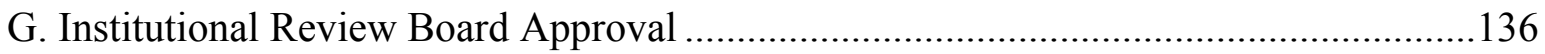

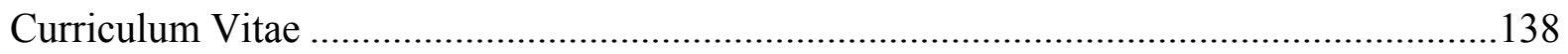




\section{List of Tables}

Table 1 Research Questions, Variables, and Analysis ............................................

Table 2 Structure of the Bolman \& Deal Leadership Orientations (Self) and (Other) Surveys..60

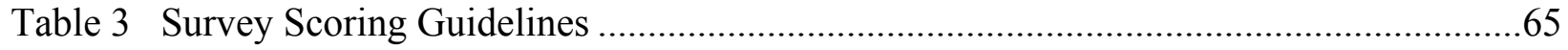

Table 4 Leadership Frame and Descriptors ..................................................................6 66

Table 5 Population, Sample, and Survey Responses .....................................................70

Table 6 Demographic Variables of County Program Coordinators.......................................71

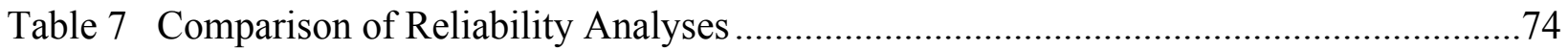

Table 8 Frequency Distribution of County Program Coordinator Leadership Styles ................76

Table 9 Mean Score, Mean Score Range, and Standard Deviation of County Program

Coordinators' Self-Rated Leadership Frames.......................................................... 78

Table 10 Correlations and Frequency Distributions by Leadership Styles and Characteristics ...81

Table 11 Frequency Distributions of Leadership Styles as Rated by County Program

Coordinators and County Extension Service Committee Members $84-85$

Table 12 Frequency Distributions of Leadership Frame Scores as Rated by County Program Coordinators and County Extension Service Committee Members

Table 13 Correlations of County Program Coordinator Ratings with County Extension Service Committee Member Mean Ratings 


\section{Chapter 1}

Introduction

Leadership is a basic element of every organization. It is manifested in the structure and relationships within families, communities, industry, clubs, and higher education institutions. Leadership is an abstract, multidimensional concept that is not easily defined. Gardner defines leadership as a process "by which an individual (or leadership team) induces a group to pursue objectives held by the leader or shared by the leader and his or her followers" (Gardner, 1990, p.1). The concept of leadership is best understood within a context such as specific organizational structures, relationships, and situations. Every type of organization strives to meet its unique demands by improving leadership strategies and leadership effectiveness. When organizations experience failure, people often point to leadership as the source of problems or weaknesses. Conversely, successes may be attributed to leadership skills and strengths. Leadership (or lack thereof) is often blamed for organizational problems. Many aspects of organizational success or failure hinge on leadership.

\section{Background}

As organizations have evolved, leadership and leader strategies have originated from authority-based systems with organizational charts, policies, and procedures. There continue to be hierarchies within organizations that operate with a top down approach. In this pattern, leaders predominantly use rational analysis to determine the best course of action and assert their formal authority in carrying it out (Lashway, 1995). However, there has been a gradual shift toward a new framework of organizational leadership in many organizations. Currently, there appears to be a more balanced approach to goals, performance, accountability, and cooperative teamwork (Fritz, 1994). Research from business and educational settings indicates that the most effective 
organizations distribute leadership broadly within the units and use a variety of leadership strategies (Bensimon, Neumann, \& Birnbaum, 1989). As organizations change in order to adapt and survive, leadership remains an important issue. "The most basic change strategy is to improve management and leadership" (Bolman \& Deal, 1997, p. 8). Leadership must change accordingly with changes in the internal and external environment of an organization. The movement of organizational leadership from a hierarchical structure to a more open, distributed system is paradoxical because of the complexity and dynamics involved in understanding the organizational leadership phenomenon.

\section{Leadership}

Many organizations seek ways to improve leadership as a strategy to improve effectiveness, efficiency, and productivity. Large or small, public or private, regardless of product or mission, all organizations look to leaders and managers to solve a wide variety of problems. Leaders within higher education organizations are under intense pressure to meet increasing societal expectations. Such changes in public expectations include documentation of student outcomes, greater accountability of fiscal resources, meeting more legal and regulatory requirements, and effective utilization of cutting-edge technology (Altbach, Berdahl \& Gumport, 1999; Birnbaum, 1991; Kerr, 1995; Leslie \& Fretwell, 1996; Siegrist, 1999). These demands require today’s leaders of educational institutions to demonstrate a more diverse set of leadership and management skills than their predecessors. Researchers and practitioners agree that a much broader repertoire of leadership practices are required to handle the complexities of today's higher education organizations (Bensimon et al., 1989; Bolman \& Deal, 1997; Lashway, 1996). 


\section{Extension Service}

Within American higher education is the cooperative extension system. The extension system is challenged to stay abreast of the changing environment and constituency needs so that its programs continue to be relevant and worthy of public support (Kellogg Commission, 2000). This challenge stems from the organization's original mission. With the passage of the SmithLever Act in 1914, the federal government created extension as a mechanism to extend the resources of the land grant universities to a broader constituency. The Smith-Lever Act states the purpose of extension work, "to aid in diffusing among the people of the United States useful and practical information on subjects relating to agriculture and home economics, and to encourage the application of the same" (Food Security Act of 1985, Section 1435 in USDA, 1986). The extension system emerged from a growing need for practical applications of research and education. The Cooperative Extension Service is a partnership between the United States Department of Agriculture (USDA) and state and local governments. Every state and U.S. territory has an Extension Service to meet the needs of its constituents through teaching, research and service.

\section{West Virginia University Extension Service - Leadership}

The West Virginia University Extension Service (WVUES) provides an educational network in each of the state's 55 counties to address a wide variety of community issues (e.g. poverty, business retention, chronic disease prevention) using a non-traditional mix of learners, faculty, staff, and volunteers. The WVUES mission states:

WVU Extension Service educators and volunteers build and help sustain collaborations and partnerships with people and organizations in West Virginia, to improve their lives and communities. Our programs and services strengthen leaders of all ages, youth, and families. 
We develop and teach best practices for sustainable agriculture, for responsible use of renewable resources, and stewardship of natural resources. We work to improve our state's communities, workforce, and the economy (West Virginia University Extension Service, 2004).

The Extension Service has nearly 100 years of experience in building strong, grass roots approaches to meet the most critical needs of the state. The organization's 435 employees include county-based faculty, support staff, state-level administrators, and specialists. The WVUES consists primarily of field or county-based faculty, also called agents. Often referred to as "change agents," extension faculty help communities, families, organizations, and individuals to improve their well-being. As field-based faculty of the land-grant higher education system, they facilitate change through teaching, research, and public service. Individually and collectively, leadership among county-based faculty is paramount to the success of the organization.

The WVUES is a dynamic organization, which has experienced significant changes in the last seven years. These changes include new administrative leadership, structural reorganizations, and the elimination of regional and mid-level managers. As part of this reorganization, increased leadership responsibilities were placed on individuals serving in a newly created County Program Coordinator role (WVUES, 1997). A County Program Coordinator (also referred to as CPC or coordinator) is designated for each county office. In many counties, there is only one faculty member and, by default, they serve as the coordinator. The responsibilities of the coordinator are part of their job description. In counties with two or more faculty members, extension administrators determine the most appropriate coordinator, based on a variety of desired qualities. Factors such as demonstrated leadership abilities and 
experience and knowledge of the organization are considered in decisions about County Program Coordinator appointments. In such cases, coordinator appointments are made and the additional duties are added to their program responsibilities. It is estimated that coordinators devote $20 \%$ of their time to this public service capacity. There is no monetary compensation provided to coordinators for the additional duties.

The effectiveness of the WVUES organization is dependent to a large degree on coordinators fulfilling their leadership roles. The strength of the extension organization lies in its quality community programming. The leadership skills and abilities of coordinators are important in assuring high quality programs. County Program Coordinators are a link between the WVUES administration and the faculty, staff, and volunteers who deliver educational programs and services. They are at the hub of educational programs and services and are known as "the face of West Virginia University" within their communities. The nature of this role includes both managerial and leadership responsibilities such as the development and management of fiscal and human resources, program coordination and reporting, support staff supervision, and communications. They develop relationships with local decision-makers and external bodies for financial and programmatic collaboration. Coordinators work closely with the County Extension Service Committee (CESC) to secure local support and advice on budgeting, staffing, and programming. This partnership and networking capacity is key to the organization's credibility and viability. Coordinators also implement organizational policies and are in a position to model leadership characteristics for other faculty to emulate. Although other groups of leaders carry out important roles in shaping the organization as a whole, the ultimate impact of County Program Coordinators' leadership is potentially greater than many other leaders. 
Changes in the structure of WVUES point to the need for county leaders who can effectively deal with the growing multiplicity of situations and problems that occur at the county level. Reorganization changes within the last decade placed greater emphasis on involvement and decentralized decision-making at the local level than in the past. This requires coordinators to employ a broader range of leadership competencies and tools to deal with issues that were previously handled by middle or upper level administrators. To date, there has been no specific plan to train and equip coordinators for their responsibilities. However, a senior administrative position was created to provide enhanced support for local leadership and issues.

Contemporary leadership studies endorse the concept of multiple leadership frames. Research demonstrates that effective leaders and managers rely on multiple perspectives or frames and those who use multiple frames of leadership are perceived by others as more effective (Bensimon, 1989, 1990; Bolman \& Deal, 1991, 1992; Heimovics, Herman \& Jurkiewicz Coughlin, 1993). Coordinator skills and behaviors must reflect changing organizational structures and expectations. However, the extent to which coordinators use multiple leadership frames is not clear. Because of the changing leadership environment within WVUES, the existing gap in extension leadership research, and the importance of county leadership, this study will explore leadership styles of County Program Coordinators.

\section{Purpose}

The purpose of this study is to examine the leadership styles of West Virginia University Extension Service County Program Coordinators. It also explores the relationship and congruence of leadership styles from the perspectives of the County Extension Service Committee members and the County Program Coordinators. Leadership frame styles will be measured by the Leadership Orientations (Self) Survey and Leadership Orientations (Other) 
Survey by Bolman and Deal (Bolman, 2001). Additional qualitative survey items will further describe leadership frame usage through critical leadership experiences. WVUES will gain understanding of coordinators' self-perceptions of leadership behaviors and skills as well as how key stakeholders, such as committee members, perceive coordinator's behaviors and skills. Conclusions from the data analyses will help identify organizational strategies to address leadership issues.

\section{Statement of the Problem}

The future success of the WVUES organization depends on strong and effective leadership at the state and local levels. Yet very little is known about leadership behaviors and skills of County Program Coordinators who serve at the local level. The gap in the literature concerning extension leadership reflects a need for studies to expand the body of knowledge. Studying extension leadership issues will provide an understanding of this specific organization, its leaders, and whether or not such issues are consistent with the current literature. In addition to bridging the gap in research, studies may provide guidance for management and leadership practices.

\section{Research Questions}

To identify and understand the characteristics, strengths, and weaknesses of the WVUES leadership core - County Program Coordinators - the following questions will guide the study:

1. Which leadership styles - no frame style, single frame style, paired frame style, or multiple frame style - do West Virginia University Extension Service County Program Coordinators perceive themselves to use as measured by the Leadership Orientations (Self) Survey? 
2. Are there statistically significant relationships between West Virginia University Extension Service County Program Coordinator leadership styles as measured by the Leadership Orientations (Self) Survey and selected background characteristics of gender, years of extension experience, program center assignment, and number of office staff?

3. Which leadership styles - no frame style, single frame style, paired frame style or multiple frame style - do County Extension Service Committee members perceive the County Program Coordinator in their county to use as measured by the Leadership Orientations (Other) Survey? How do these results based on County Extension Service Committee member (other) perceptions compare with the results of County Program Coordinator (self) perceptions (Research Question 1)?

4. Are there statistically significant relationships between County Program Coordinator leadership styles as identified by County Extension Service Committee members and County Program Coordinator leadership styles as identified by the coordinators?

5. What are the critical leadership incidents as described by County Program Coordinators, as measured by the Leadership Orientations (Self) Survey? How do these descriptions compare to the leadership styles?

\section{Significance of the Study}

This study may contribute to the body of knowledge in the area of extension leadership and to the practical application of this knowledge. The findings may be of interest to WVUES administrators, County Program Coordinators, and County Extension Service Committee members as well as to other state and national extension administrators as well. While this study pertains to West Virginia's 55 counties, there are 3,150 counties nationwide. As a result, county extension leadership research is relevant to every state and territory. There are different 
variations in the titles and specific duties of county leaders among the state extension organizations. However, this study should prove to be of national relevance because local leadership positions exist in some form in every state.

The knowledge of leadership patterns is an important factor in strengthening organizational leadership. Research is needed to identify factors associated with leadership performance (Bassano, 1987; Boone, 1988; Broshar \& Jost, 1995; Brown, Birnstihl \& Wheeler, 1999; Cooper \& Graham, 2001; Cox, 1989; Ganter, 1989; Graham, 1982; Gunderson, 1994; Harrison, 1984; Haynes, 2000; Ladewig \& Rohs, 2000; Norman, 1988; Peterson, 1987; Radhakrishna, Yoder \& Baggett, 1994; Smalley, 1985; Whiteside, 1985). Specific contributions of this research may include greater knowledge and understanding of how leadership behaviors and styles of extension faculty are perceived by others. Administrators may find this study significant because it may alert them to problems and opportunities. In light of the trend toward increasing expectations and greater dispersion of leadership throughout the extension organization, this knowledge and understanding may be crucial in enhancing extension's leadership effectiveness. Scholars of educational leadership, particularly those who are unfamiliar with the extension system, may expand their understanding of the organization and how extension leadership functions.

An increased knowledge of county leader skills and behaviors may form the basis of future training and other improvements (Cooper \& Graham, 2001; Haynes, 2000; Radhakrishna, Yoder, \& Baggett, 1994; Whiteside, 1985). This could include the development of a set of competencies, role definitions, expectations, and performance evaluation measures. A clearer picture of role expectations and requirements may help in evaluating human resource processes and decisions. With approximately $80 \%$ of WVUES funds paying for salary and benefits, it is 
critical that the organization hire the most competent leaders. Research that leads to a specific set of desirable qualifications may help WVUES match prospective applicants to job assignments. And, once hired, county leaders can be nurtured through professional development experiences to build on leadership strengths and remedy weak areas. The specific training and support needs of County Program Coordinators should receive appropriate attention. Adequate role preparation of leaders is essential to the success of these individuals. Lastly, exploring both the perspective of the county leaders and that of a representative constituent group is significant. Through participation in this study, each group can gain new insight into county leadership issues.

With a fresh perspective of extension's county leadership, extension "customers" volunteers and the general public - may benefit from this study. If this research information is used to improve organizational strategies, offices and programs may benefit from more effective management. The public demands and expects excellence and accountability. It is crucial that extension live up to the expectations of community leadership and quality programming. The use of this research information is one way to respond to this public expectation.

WVUES needs to identify and fully understand the characteristics, strengths, and weaknesses of its county leadership core - County Program Coordinators. This information and insight may improve organizational strategies and further develop effective leaders. The ability to understand coordinators as individuals and as a group is a necessary first step in maximizing the leadership potential within the organization. Specific knowledge of their leadership characteristics, strengths, and weaknesses provide a way to assess one critical part of WVUES' potential.

There is no existing research on WVUES county leadership. There is a generic County Program Coordinator job description that outlines the basic purpose of the assignment, essential 
functions, and tasks. However, there has been no assessment of needs and there is currently no training program being conducted to strengthen job-specific leadership skills. This research will assist in addressing county leadership issues and building organizational knowledge and understanding of coordinator leadership in general. Given contemporary leadership philosophy that supports the notion of multi-dimensional leadership styles, this research will explore the extent that coordinator leadership self-perceptions are, in fact, multi-dimensional. It will also clarify how the current leaders describe their skills, behaviors, and strengths related to their role. The ability of state-level extension administrators to accurately understand local leaders' points of view may help them engage the coordinators, improve decision making, and relate to each county's unique situational context. The implications of this study have potential to improve many aspects of the function and climate of the WVUES organization.

Another point of significance to this study is the current environment of the extension system. High public expectations pose challenges to organizational leaders (Ladewig \& Rohs, 2000; Patterson, 1995). As one extension administrator from another state articulated, "Extension is long overdue for fundamental change. There is a palpable growing dissatisfaction with the stodgy, bureaucratic, command-and-control structure found throughout extension, while shrinking budgets, an eroding political base, and a loss of prestige have put Extension in a tenuous position" (Patterson, 1995). In the search for solutions to these problematic issues, extension leaders at all levels are expected to rise to the challenge. Leaders need a variety of tools and strategies. However, there is a lack of current research in the area of extension leadership at the county level relevant to what skills, behaviors, and leadership orientations county leaders must possess. Without knowledge and understanding of leader skills and 
behaviors, extension systems cannot maximize the leadership potential of its county leadership core (Radhakrishna, Yoder, \& Baggett, 1994).

This study will contribute to the literature by further testing the Bolman and Deal instruments with the extension organization and its stakeholders. There appears to be a shortage of studies using these instruments with an extension population. Therefore, this research will extend the existing literature on extension leadership orientations. The research may also stimulate further study of leadership within the national extension system. There is a heuristic value to examining this with a segment of extension leaders who have received minimal attention in the literature. Many leadership researchers caution against oversimplified categories of leadership and singular research perspectives (Chaffee, 1989; Neumann \& Bensimon, 1990). Therefore, diverse approaches and research techniques in studying leadership frames of higher education leaders are incorporated into the design of this study.

The changing environment and challenges extension faces indicates the need for the organization to develop its leaders to most effectively function. This research provides new and significant information to help accomplish this task. It is vital that the organization use solid research to develop leadership strategies consistent with extension's commitment and mission to extend and apply research-based knowledge. The phrase "putting knowledge to work" is as appropriate to extension programs and clientele as it is to the organization and leaders.

\section{Terms and Definitions}

It is essential to define concepts that will be referred to throughout the study. The following explanation of terms may assist in understanding the research study.

1. Extension Service: the state organization which carries out the mandate for outreach education of the land-grant higher education institution. 
2. Extension System: the state or national structure inclusive of all faculty, staff, programs, and resources.

3. West Virginia University Extension Service (WVUES): an organization created by federal and state legislation to extend educational opportunities and research-based knowledge to West Virginia's citizens.

4. County Extension Office: a WVUES office located in any one of West Virginia's 55 counties.

5. County Program Coordinator: a county-level WVUES employee and faculty member who has been designated to devote $20 \%$ or more time to coordinate extension programs in the county, facilitate internal and external communication, and develop resources (West Virginia University Extension Service, 2001).

6. Co-Worker: a WVUES employee and faculty member who is a peer of the County Program Coordinator, works in the same county or another county office, but does not necessarily serve as a County Program Coordinator.

7. Faculty Member: an extension employee who holds a full-time faculty position at either the county or state level and has a minimum of a master's degree.

8. County Staff: non-faculty employees who work in support of extension programming; this includes county and WVUES employees with titles such as secretary and program assistant.

9. Center Director: a state-level WVUES administrator with leadership responsibility for one of two units - Agriculture, Natural Resources, and Community Development (ANRCD) and 4-H and Youth, Family, and Adult Development (4-HYFAD). 
10. Program Center Assignment: formal assignment of program responsibility within one of two WVUES units - Agriculture, Natural Resources, and Community Development (ANRCD) and 4-H and Youth, Family, and Adult Development (4-HYFAD).

11. Director of Extension and Public Service: state-level WVUES administrator with leadership responsibility for the West Virginia University Extension Service.

12. County Extension Service Committee (CESC): a committee mandated by West Virginia state law to serve in an advisory capacity in each of the state's 55 counties; the committee includes eight representatives of specified constituent groups (West Virginia Agricultural Laws, 1915, 1990).

12. Gender: the sex of a study participant, male or female.

13. Years of Experience: the number of years of full-time work experience in a county-level extension faculty position; the three categories for years of experience used in the study are less than 10 years, 10-20 years, and more than 21 years.

14. Frame Choice(s): the leadership frame(s) an individual chooses to use in any given situation.

15. Leadership Frames: organizational schemata by Bolman \& Deal by which leaders can view any given situation, organize information, and make decisions; the four leadership frames are structural, human resource, political, and symbolic (Bolman \& Deal, 1997).

16. Leadership Style: the predominant pattern of leadership frame(s) and frame choice(s) perceived to be used by study participants as determined by their mean score of 4.0 or greater on the Leadership Orientation Survey by Bolman \& Deal. 
17. No Frame Leadership Style: no predominant leadership frame of the four possible frames, as determined by a study participant's mean score of 4.0 or less on the Leadership Orientation Survey by Bolman \& Deal.

18. Single Frame Leadership Style: frequent use of one leadership frame of the four possible frames as determined by a study participant's mean score of 4.0 or greater on the Leadership Orientation Survey by Bolman \& Deal.

19. Paired Frame Leadership Style: frequent use of two leadership frames of the four possible frames as determined by a study participant's mean score of 4.0 or greater on the Leadership Orientation Survey by Bolman \& Deal.

20. Multiple Frame Leadership Style: frequent use of three or four leadership frames of the four possible frames as determined by a study participant's mean score of 4.0 or greater the Leadership Orientation Survey by Bolman \& Deal; also, the ability to concurrently and flexibly use three or four leadership frames in a given situation.

21. Leadership Effectiveness: the ability of a leader to use a multiple frame leadership style, particularly in the symbolic and political frames, in performing leader responsibilities (Bensimon, 1989; Bolman \& Deal, 1999; Neumann \& Bensimon, 1990).

22. Structural Frame: the leadership perspective that focuses on formal roles, chain of command, responsibilities, policies, and goals (Bolman \& Deal, 1992, 1997).

23. Human Resource Frame: the leadership perspective that focuses on human needs and relationships based on the assumption that an organization's human resources are the most valuable resources (Bolman \& Deal, 1992, 1997).

24. Political Frame: the leadership perspective that focuses on conflict and competition for power and resources among groups and individuals (Bolman \& Deal, 1992, 1997). 
25. Symbolic Frame: the leadership perspective that focuses on the importance of rituals, ceremonies, stories and other activities that give meaning and interpretation of the organization's work (Bolman \& Deal, 1992, 1997).

26. Critical Leadership Incidents: the significant leadership accomplishments and greatest challenges as reported by County Program Coordinators on Section III of the Leadership Orientations (Self) Survey.

\section{Assumptions and Limitations of the Study}

The following assumptions and limitations are relevant to this study:

1. Leadership is inherent in all persons.

2. The capacity of a leader to reframe and use multiple frames - structural, human resource, political, and symbolic - increases the potential for successful and effective leadership performance.

3. Data is reported through a survey and the accuracy of these methods will limit the study. It is assumed that the participants will respond accurately and honestly to survey and interview questions.

4. The instrument used in this study, like any tool, will not provide a comprehensive measurement of leadership.

5. Because of the complexity of leadership behaviors and skills, the survey only measures a small number of the potential aspects of leadership.

6. The validity and reliability of the instrument has been tested with credible results. However, there are always some limitations with the accuracy of each item in measuring what it is intended to measure. 
7. The "other" version of the survey instrument has been used with peers and subordinates, but has not been tested with stakeholders.

8. This study pertains to a single organization, the West Virginia University Extension Service (WVUES), and its uniqueness and idiosyncrasies may limit the extent to which results may be generalized to other organizations. The organizational context of the WVUES provides a unique environment such that research results may or may not be applicable to other organizations.

9. Study participants include County Program Coordinators, which is only one group of leaders within WVUES. As a result, research data only reflects a partial picture of overall organizational leadership.

10. The County Program Coordinator role is relatively new. As such, clear definitions, expectations, training, and accountability systems have not been well defined.

11. Leadership is a context-dependent concept in that different situations require different styles and frames of leadership.

12. Organizations are dynamic entities. There are many uncontrollable variables that may impact the study. Changes in the external environment as well as an organization's people, behavior, and events must be recognized.

13. This study examines leadership frame orientations at one point in time.

14. There are multiple realities that co-exist in organizations. Consequently, any study may or may not capture the entire gamut of these perspectives.

15. The researcher is an active participant in the WVUES organization and there are inherent drawbacks from this. 


\section{Chapter 2}

\section{Review of Related Literature}

This study explores the leadership orientations of County Program Coordinators employed by the West Virginia University Extension Service (WVUES). The purpose of this chapter is to provide a cognitive map or context for the research study. The following review includes literature relevant to Bolman and Deal's leadership model and the variables of this study. Many leadership theories have been developed over the last several decades and many of these theories are encompassed in Bolman and Deal's comprehensive model. Therefore, the chapter includes an overview of a broad array of leadership theories. Major theories include trait theory, behavioral theory, situational and contingency theory, and power and influence theory. These are compared and contrasted with the four frame model. The final section explores the research literature on Bolman and Deal's leadership frames to bring into focus the specific body of knowledge germane to this study.

\section{Leadership}

Leadership is a word with many meanings and uses. It is frequently used to refer to specific concepts such as individuals, groups of individuals, personal qualities, and abilities. When used in more abstract ways, leadership may refer to influence, an organizational movement or a general style. Bennis (1989) contends that leadership is like beauty: it is hard to define, but you know it when you see it. Gardner defines leadership as a process "by which an individual (or leadership team) induces a group to pursue objectives held by the leader or shared by the leader and his or her followers" (Gardner, 1990, p. 1). For centuries, humans have searched for answers to the enigma of leadership. More importantly than establishing a precise definition is the ability 
of researchers and practitioners to develop theories with which effective leadership may be better understood and applied.

\section{Bolman \& Deal's Multi-Frame Leadership Model}

The story of the blind men who describe an elephant in very different and distinct ways could be leaders attempting to describe an organization. There are multiple perspectives, or "frames", through which to view an organization. The decisions and actions of different leaders depend on how a situation, decision, or task is framed. This is the belief of two contemporary leadership researchers, Lee Bolman and Terrence Deal. Their model revolves around four leadership frames: structural, human resource, political, and symbolic. Each frame is based on various aspects of organizational behavior (Bolman \& Deal, 1984, 1997).

The structural frame emphasizes organizational goals, roles, policies, and hierarchies. "Structural leaders value analysis and data, keep their eye on the bottom line, set clear directions, hold people accountable for results, and try to solve organizational problems with new policies and rules or through restructuring" (Bolman \& Deal, 1992, p. 270). This frame is sometimes referred to as the bureaucratic frame. Using metaphors, this frame would be likened to a factory or machine because of its emphasis on systems and authority (Bolman \& Deal, 1997).

The human resource frame views organizations in terms of its people. Leaders using this frame are attuned to the relationships, needs, and motivation of employees, clients, and stakeholders. Leaders seek participation, consensus, and democratic decision-making processes. Their goal is to help empower people to realize their potential through interpersonal skills. Investing in and attending to the "fit" between the employees and the organization is of paramount importance. Bolman and Deal use the metaphor of a family in describing how leaders regard this frame (Bensimon, 1989; Bolman \& Deal, 1992, 1997). 
The political frame concentrates on the issues of power and resources. This frame assumes that competition over scarce resources drives the organization. Using this frame, leaders can see power, coalition building, and networking as tools to accomplish tasks and goals. From this frame's perspective, differences in values and interests among coalition members naturally result in conflict. The most important process within organizations is the negotiation of this conflict and jockeying for power. The political frame metaphor is a jungle (Bolman \& Deal, 1997).

The symbolic frame focuses on culture and meaning. The meaning and values behind organizational behaviors and actions are important to leaders using this frame. Leaders look beyond the obvious, day-to-day activities, and use symbols, ceremonies, and stories to shape the culture and bring meaning to what employees may find too confusing or complex to fully understand. Symbolism may bring order, clarity, and predictability to an organization. Symbolic and cultural issues are more prevalent in the literature and in research since the 1980's. Tierney offers three recommendations to leaders about their role in symbolism: (1) symbols demand corroboration, (2) use symbols consistent with the organizational culture, and (3) use all forms of symbolism (Tierney, 1989). The symbolic frame metaphor is a theater or circus in which actors are motivated by inherent beliefs and seek inspiration through their work (Bolman \& Deal, 1997).

Together, the four lenses or frames of the Bolman \& Deal model are tools with which leaders understand the behavior of the organization and define their roles. Separately, each lens provides leaders with ways to view, understand, make sense, and problem solve. A central tenet of the model is flexibility with which skilled leaders can employ the four frames. Bolman and Deal stress that "Wise leaders understand their own strengths, work to expand them, and build teams that can provide leadership in all four modes - structural, political, human resource, and 
symbolic" (Bolman \& Deal, 1997, p. 317). Several contemporary scholars espouse the Bolman and Deal model as an effective way of understanding leadership behavior (Bensimon, 1989; Birnbaum, 1989; Chaffee, 1989; Neumann, 1989; Neumann \& Bensimon, 1990). A leader's use of multiple frames is vital as higher education environments become increasingly complex. Birnbaum summarized in a discussion of research on college and university presidents:

The important point is not whether one theoretical approach is more correct than another, but rather that presidents and other leaders live in complex and turbulent worlds. The more restricted their view of leadership, the more limited their repertoire of behavior will be. Directive leadership, expected and desired in some situations, can lead to conflict and disruption in others. Complex presidents, with rich understandings of the many roles they play, may be more likely to tailor their behavior to the requirements of emerging situations and thus increase their effectiveness" (Birnbaum, 1989, p. 135).

And, as Bensimon expressed so succinctly, "Frames influence what leaders see and do" (Bensimon, 1989, p. 108).

The Bolman and Deal model may be considered a culmination of leadership theories. It encompasses trait theory, behavioral theory, situational theory, contingency theory, and power and influence theory. The following section describes the development of these types of theories, how they relate to the Bolman and Deal model, and the elements of the four leadership frames.

\section{Trait Theories}

Trait theories were the first approach used in the attempt to understand leadership. The Great-Man Theories, as they were called, were based on the premise that the personal attributes of great men set the course of history. Researchers hoped to find the keys to effective leadership by identifying individuals' characteristics and differentiating them from followers' traits. 
Research focused on such qualities as physical and psychological attributes, intelligence, personality, and other individual traits. Some traits were thought to be innate and some learned (Bass, 1981). This area of research was prevalent in the early 1920's and coincided with the psychological testing movement. Most of these studies involved leaders in business, government, and the military. Studies did identify traits that were more prevalent in leaders than non-leaders. In fact, many leadership traits are cited in the literature. According to Bass' review of trait research (1981), the factors most often associated with leadership are capacity, achievement, responsibility, participation, status, and situation. However, findings were inconsistent and researchers began to recognize the importance of organizational situational variables. As noted by Stogdill (in Fiedler, 1974, p. 2), "leadership must be conceived in terms of the interaction of variables which are in constant flux and change. The factor of change is especially characteristic of the situation." Consequently, trait research shifted from a narrow perspective of identifying a finite set of leader traits to identifying variables of leader effectiveness - personality, motivation, administrative skills, and the situation itself (Bass, 1981; Bensimon et al., 1989; Hersey \& Blanchard, 1982; Hoy \& Miskel, 1996; Yukl, 1994). Research has demonstrated that leader behaviors are better predictors of performance and effectiveness than are measures of leader traits (Clark \& Clark in Clark, Clark, \& Campbell, 1992, p. 5). More recent approaches to studying leader traits incorporated more complex variables and, overall, resulted in findings more consistent than those found in earlier trait research. It is interesting to note that Birnbaum's (1989) interviews with college and university presidents revealed that $25 \%$ described trait theories as part of their definition of leadership. In summary, trait research shows that some leader qualities increase leader success, but none of the traits assure a leader's success (Yukl \& Van Fleet in Dunnette \& Hough, 1990, pp. 150-154). 
Although leadership theories have developed beyond the more simplistic concept of traits as an isolated and predictive variable, it is important to acknowledge that traits can contribute to a leader's success. One contemporary group of scholars contends that leadership calls for more attention to the intangible human traits of ethical commitment, character, self-knowledge, risk taking, courage, and long-range vision (Bolman \& Deal, 1994). Current thoughts on leadership traits emphasize the importance of more ethereal qualities of character and values (Tierney, 1989). Bolman and Deal's model relates to trait theories in that within each leadership frame some specific traits are common to leaders who use that frame. For example, effective political leaders are persuasive. They are also adept at establishing personal contacts and networks. The traits attributed to each frame could be described as personality or skill traits. Therefore, the Bolman and Deal model integrates traits and trait research into four leadership frames.

\section{Behavioral Theories}

Another area of leadership research concerns leadership behaviors. The Hawthorne studies of the 1920's stimulated interest in organizational issues related to motivation, behavior, and the social conditions of work. This, and other studies, added important insights related to leadership behaviors. At the same time, the fields of social sciences and psychology were flourishing, thereby fueling attention to research, particularly in industrial settings. Most of this research was conducted using methods such as observation, logs, and interviews (Yukl \& Van Fleet in Dunnette \& Hough, 1990, p. 154).

Several significant theories helped to shape current understanding of leader and follower behaviors. Need, value, and motive theories stress the importance of an individual's internal tensions that result in motivation and behavior. Maslow's need hierarchy is a well-recognized theory based on the premise that humans have innate needs. Needs are arranged in a hierarchical, 
sequential manner, and individuals strive to satisfy lower level needs (e.g. physiological, safety, and security) before pursuing higher level needs (e.g. belonging, esteem, and self-fulfillment) (Hersey \& Blanchard, 1982; Hoy \& Miskel, 1996; Kanfer in Dunnette \& Hough, 1990, p. 81$83)$.

McClelland's theory of achievement, or n-achievement theory, states that people's behaviors are based on learned experiences and the values and positive or negative feelings they associate with the experience. Individual perceptions and achievement motivations in any given situation are attributed to a value set (Hersey \& Blanchard, 1982; Hoy \& Miskel, 1996; McClelland, 1985). The theories by Maslow and McClelland are well-known, but have not been substantiated as valid, universal frameworks, largely because of problems with the lack of consistency and predictability (Kanfer in Dunnette \& Hough, 1990, pp. 83-86).

A third noteworthy theory related to human needs is Herzberg's motivation-hygiene theory. Based on professional employees in industrial settings, Herzberg identified factors that tend to satisfy needs. Motivators are characteristics of the job itself. When motivators are present, an individual's ability to perform is enhanced. Hygiene factors are environmental characteristics which, when satisfied, tend to reduce dissatisfaction but provide little motivation. This theory highlights the two different and distinct sets of factors - hygiene and motivator - and how they impact employee attitudes. Herzberg went on to contribute to research in the area of job enrichment and redesign as methods of enhancing worker motivation (Hersey \& Blanchard, 1982; Herzberg, 1982; Herzberg, 1966; Hoy \& Miskel, 1996).

Cognitive choice theories are another set of theories that help explain motivation and behavior. Vroom's expectancy theory focuses on three elements: (1) the individual's expectancy that they can perform the task, (2) the instrumentality or perception that task performance will 
lead to anticipated outcomes and rewards, and (3) the valence or positive or negative value associated with the outcome. Thus, according to expectancy theory, a leader's behavior is the result of the interaction of expectancy, instrumentality, and valence (Bowditch \& Buono, 1985; Hersey \& Blanchard, 1982; Kanfer in Dunnette \& Hough, 1990, p. 115). This theory has been established as a valid predictor of work satisfaction and, to a lesser extent work behavior in a variety of organizational environments (Hoy \& Miskel, 1996).

Another model is attribution theory. The basic idea of this theory is that individuals make inferences about an event or situation in order to rationalize what happened. Again, three elements are analyzed: (1) the locus or cause, (2) the stability, and (3) the controllability of the event. These two cognitive choice theories yield a valuable and more detailed perspective relevant to the determinants of leadership behavior (Kanfer in Dunnette \& Hough, 1990). Metacognitive and self-regulation theories conceptualize the interaction between intentions, goals, behavior, and performance. Two such theories are self-efficacy and goal-setting. Bandura's self-efficacy theory is based on an individual's view of their future capacity to perform at a certain level. It extends the concept of behavior based on attribution and expectancy and includes other influential factors of beliefs about self-efficacy, mastery of experiences, and assessment of difficulty and capacity. This taxonomy is more multidimensional than past approaches, distinguishing between various intrinsic and extrinsic motivators, and the anticipated behavior outcomes (Kanfer in Dunnette \& Hough, 1990).

A second metacognitive theory is Locke's goal-setting theory in which individuals base a goal on a variety of factors (e.g. attribution, values, self-efficacy), evaluate goal content and intensity, determine strategies for goal achievement, carry out the goal, and incorporate feedback into future goal efforts (Locke, 1990). Hoy \& Miskel (1997) emphasize the widespread support 
for goal-setting theory and its practical application and integration with other theories of motivation. While not specific in their reference to leadership motivation and behavior, the aforementioned theories are meaningful to leaders in that leaders may gain in their own selfanalysis as well as in understanding of how others think and interact within the work environment.

The Ohio State Leadership Studies of the 1940's looked at two dimensions of leader behavior, initiating structure, and consideration. Initiating structure dealt with organizational skills while consideration was defined as behaviors that focus on the leader-subordinate relationship. A leader behavior description questionnaire (LBDQ) provides an assessment tool with which a leader's scores translate into an individualized leadership style (Bensimon et al., 1989b; Hersey \& Blanchard, 1982; Hoy \& Miskel, 1996). Conclusions from these studies were: (1) initiating structure and consideration are fundamental to leadership; (2) frequent behavior in both dimensions are associated with effective leader behavior; (3) superiors evaluate their own leadership behavior according to the initiating structure, and conversely, subordinates focus on a leader's consideration; and (4) there is only a slight relationship between leaders' descriptions of their behaviors and subordinates' descriptions of the leaders' actual behaviors (Halpin in Hoy \& Miskel, 1996, p. 383).

The term leadership style subsequently emerged as a way of describing a pattern or set of behaviors characteristic to an individual leader (Fiedler, 1974). Michigan State researchers conducted similar studies to determine the behavioral differences between effective and noneffective leaders. These studies are significant because they reveal a way to conceptualize two critical dimensions of leader behavior; initiating and consideration. These two dimensions have been found to be pervasive in many types of organizations in the United States and in other 
countries (Clark \& Clark in Clark et al., 1992). Studies have shown that leaders and subordinates have distinct perspectives on these two dimensions. In essence, a leader's consideration is very important to subordinates, yet leaders seem to emphasize initiating structure. Not surprisingly, effective leadership is associated with high scores in both initiating and consideration and the two dimensions are not mutually exclusive (Bensimon et al., 1989; Hoy \& Miskel, 1997).

Similar to the LBDQ, the Managerial Grid proposed by Blake and Mouton deals with leader concerns along the dimensions of people and production (Blake and Mouton, 1964; Hoy \& Miskel, 1997; Bensimon et al., 1989). Research using these models reveal that effective leaders scored high on both dimensions of tasks and relationships, while recognizing that the uniqueness of any given situation may determine if one or both dimensions was the overriding consideration. Several assumptions of these theories are questionable. Although the most effective leadership style clearly emphasizes both people and productivity, there is no "perfect" style, as some models may imply. Another flaw with models that classify leadership behavior is there is no consensus on the categories in the various systems. The assumption that leader behavior causes changes in subordinate performance may be inherently flawed. Additionally, leader behaviors may not realistically fit into distinct and mutually exclusive categories. Furthermore, the relative importance of task and relationships vary widely with the situation (Yukl \& Van Fleet in Dunnette \& Hough, 1990, p. 157).

Several theories focus on the humanistic perspective of leadership behavior. MacGregor's 1960 Theory X and Theory Y on managerial perceptions and beliefs brought to the forefront the idea of potential self-motivation within an organization. Theory $\mathrm{X}$ is a set of assumptions held by managers about human nature in which most people prefer to have their work structured and controlled. The opposite of Theory X is Theory Y. Its premise is that people desire to be creative 
and self-motivated in contributing to the organization's goals. In concept, proper management strategies shaped by an accurate understanding of human nature will release the potential in individuals for greater productivity (Bolman \& Deal, 1997; Fiedler, 1974; Hersey \& Blanchard 1982; McGregor, 1960). Expanding on this theory, Argyris identified interpersonal behaviors and group norms linked to Theory X and Theory Y. Argyris, like MacGregor, questioned organization-employee relationships and conflicts. He contends in his Maturity-Immaturity Theory that organizational structures, policies, and rigid, hierarchical management practices underestimate human needs, and impede worker satisfaction, growth and productivity. Likert was also concerned about negative consequences of traditional management practices and proposed increased participation and a more decentralized approach. This philosophy about leadership contends that natural human tendencies that are self-directed and mature are squelched by the inherent organizational conditions (Bass, 1981; Bolman \& Deal, 1997; Bowditch \& Buono, 1985; Fiedler, 1974; Hersey \& Blanchard, 1982).

As with previous theoretical models, behavior theories have made important contributions to the field, but they have drawbacks and limitations. Because of the complexity of human behavior and behavioral variables, objective, valid measurement tools and methods pose difficult problems. Issues of causality, the changing nature of behaviors and situations and other confounding variables make it impossible to conclude that a leader's behavior is the dominant or central factor. Behavior theories in general have not proven effective in predicting desired outcomes. However, they have provided a broad context for understanding leader and follower behavior (Bensimon et al., 1989). It is possible that researchers have paid too much attention to discovering a magic formula for leadership behavior and focused on narrow, arbitrary taxonomies and measurement instruments (Yukl in Dunnette \& Lough, 1990, p. 160). Current 
research trends point to the need for a more cohesive, cross-disciplinary approach (Kanfer in Dunnette \& Lough, 1990, p. 157).

Behavioral theories and research are evident in Bolman and Deal's multi-frame leadership model. Like behavioral theories, the basic element of Bolman and Deal's framework is the leader and his/her individualized behavior or style. Bolman and Deal stress the unique, personal nature of being an effective leader (Bolman \& Deal, 1997). Leaders must learn to understand and manage the factors that affect their own behaviors (e.g. motivation, expectancy, attribution, selfefficacy, maturity) as well as the behaviors of other leaders, subordinates, and clients. It is essential to understand motivational theories and human cognitive processes. The human resource and the symbolic frames pertain more directly to the behavioral theories than the other frames. From the perspective of the human resource frame, leaders must be concerned with the human needs within the organization, as research from the Ohio State Leadership Studies, Bandura, Likert and others have revealed. Similarly, the symbolic frame recognizes that people have an innate need and desire for inspiration and shared values in their work. This view is supported by research by McClelland, Argyris, and others.

Prudent leaders should also be wary about adopting theories that may be oversimplified and incomplete. Individual and organizational behaviors are unpredictable and dynamic, which limits the ability to use behavioral theories exclusively as a guide. Leaders must go beyond this level of understanding to a deeper appreciation of situational variables (Bensimon, 1989; Bolman \& Deal, 1997; Birnbaum, 1989; Chaffee, 1989; Hoy \& Miskel, 1996). The four leadership frames are more pluralistic and overlapping than the aforementioned theories. 


\section{Situational and Contingency Theories}

Situational and contingency theories look at characteristics of situations that could be attributed to the leaders' success. There is considerable overlap in situational and contingency theories. For the purpose of this discussion, these theories are treated as one integrated area of leadership research. All assume that effective behavior depends on the nature of the situation. Contingency theories focus on factors outside the organization. A variety of factors have been suggested as determinants of effective leadership: organization structure, role characteristics, subordinate characteristics, and internal and external environmental factors. Studies of situational factors demonstrate that a situation has direct influence on leaders. The interaction of situational factors and leadership traits is key to producing certain leader behaviors that lead to effectiveness (Bensimon et al., 1989; Hoy \& Miskel, 1996; Yukl \& Van Fleet in Dunnette \& Hough, 1990, pp. 167-173). Leaders who are perceptive in understanding human traits and situational variables may adapt their actions appropriately and effectively.

An outgrowth of situational leadership research is the substitutes-for-leaders or substitutesfor-hierarchical-leadership model. The basic premise of this model is that, in some situations, effectiveness is attributable to subordinate, task, and organizational factors instead of leadership (Kerr \& Jermier, 1978). While it poses interesting ideas related to the interactive nature of variables, this model faded out in favor of a more dynamic approach. However, there have been some recent articles in the literature that demonstrate the relevance and usefulness of the substitutes-for-leaders theory to higher education (Bensimon et al., 1989; Birnbaum, 1989; Dever, 1997).

Contingency theories focus on the interactive nature of leader behavior and situational factors. Effective leadership behavior is contingent on the situation. Fiedler's Leadership 
Contingency Model classifies group situations and task or relationship-oriented leadership patterns to determine the most favorable combination. The model uses a "Least Preferred CoWorker" instrument to determine behavioral preferences (Fiedler, 1974). The postulates of the theory are: (1) leadership style is determined by the leader's motivational system; (2) situational control is contingent on group climate, task structure, and position power; and (3) group effectiveness is contingent on the leader's style and control of the situation. Therefore, the most effective organizational leadership strategy is to position leaders in situations that match their strengths with the needs of the group. The work by Fiedler and others raised the issues of personsituation fit and training and development efforts to adjust for a favorable match (Bass, 1981). Since his original model was proposed, Fiedler developed a cognitive resource theory that incorporates the important variables of a leader's intelligence, competence, and experience. Research has been generally supportive of Fiedler's theory, demonstrating the need for an integrated, adaptive approach to leadership (Bensimon et al., 1989; Hersey \& Blanchard, 1982; Hoy \& Miskel, 1996).

Other noteworthy contingency models attempt to prescribe or predict outcomes based on a variety of variables. Hersey and Blanchard's Tri-Dimensional Leadership Effectiveness Model integrates an effectiveness continuum with leader task and relationship behavior dimensions. This model describes observed leader behaviors as opposed to attitudes, values, and predispositions. Leaders adapt their behavior according to the situational demands and subordinates' needs and maturity in relation to the task. (Bensimon et al., 1989; Hersey \& Blanchard, 1982). Similarly, the Vroom-Yetton Model of leadership and decision-making provides a diagnostic process to guide leaders. Problem attributes and situational demands are analyzed to determine which specific decision process would yield the most favorable results. 
This model is evaluative and prescriptive in nature because it describes the actions and behaviors a leader should consider to maximize the effectiveness of the decision in a given situation (Bensimon et al., 1989; Vroom \& Jago in Katz, Kahn, \& Adams, 1980, p. 384).

Another related theory is the path-goal theory. The theory proposes that an integrated goal setting system at both the individual and organizational levels is an effective leadership tool. Effective leaders assist others in setting and achieving goals which results in increased satisfaction, motivation, and productivity. Various factors must be considered to facilitate the most effective goal-setting strategies. The unique aspect of this theory is not the concept of goal setting itself, but the relationship between leadership style and task structure. The dimensions of initiating and consideration are used in helping leaders formulate the appropriate mix of ambiguity/clarity and directiveness/supportiveness (Bensimon et al., 1989; Hersey \& Blanchard, 1982; House, 1971; Hoy \& Miskel, 1996; Locke \& Latham, 1984). The path-goal theory is generally supported but is not always regarded as adequately tested in a wide variety of organizational settings (Hoy \& Miskel, 1996; Yukl \& Van Fleet in Dunnette \& Hough, 1990, p. 169).

This review has covered the most prominent situational and contingency models, theories, and frameworks of leadership. Research demonstrates that early studies did not adequately capture the specific behaviors and practices needed for a given situation. Some were based on questionable assumptions. Others were only tested with limited populations. Situational variables (e.g. task structure and complexity) are often ambiguous and difficult to translate into behavioral guidelines for leaders (Yukl \& Van Fleet in Dunnette \& Hough, 1990, p. 173). Trait, behavioral, and situational theories are regarded as limited because leadership is more than an effect of a single set of forces (Bass, 1981). Hoy and Miskel comment that it is 
counterproductive to restrict the study of leadership to either traits or situations (Hoy \& Miskel, 1996). The weaknesses of these theories must be recognized.

Among the many models, contingency models have made some distinct contributions to leadership studies. Contingency models may be regarded as the most influential theories of leadership to date because they help explain traits, situations, behaviors, and effectiveness (Hoy \& Miskel, 1996). Situational and contingency theories brought out several significant perspectives in the development of leadership theories. First, no one style of leader is best or appropriate for every situation, and subsequently, there is no one best way to influence people (Hersey \& Blanchard, 1982). Second, a leader's flexibility and adaptability are vital. As leadership theories continue to evolve, it becomes clearer that there is no single "ideal" leadership style. Different situations and environments call for different leader traits and behaviors. This is the basic premise of Bolman and Deal's four frame leadership model. Effective leaders must be able to evaluate various situations using each of the four frames and adapt their skills accordingly (Bolman \& Deal, 1997).

\section{Power \& Influence Theories}

Power and influence are fundamental principles of leadership. Organizations are the arenas in which power and politics are acted out (Hoy \& Miskel, 1996). Leadership theories have been developed which categorize different types of power. The differences between these theories are in the focus. Weber proposed three types of power according to different kinds of authority or legitimacy: charismatic (personal trust), traditional (position), and legal (laws). Peabody and Blau and Scott proposed similar concepts (Hoy \& Miskel, 1996). French and Raven looked at the sources of power and identifies five kinds of power: reward, coercive, legitimate, referent, and expert. The source of power of the first three is organizational and power of the latter two is 
associated with the individual (Bensimon, 1989). Etzioni developed another typology in which the focus is the means used to make employees comply with organizational directives. Etzioni's types of power - coercive, remunerative, and normative - are applied to subordinates in varying degrees. This results in subordinate reactions to power, or zones of involvement. This research led to a greater understanding of different power and compliance relationship patterns among organizations (Hersey \& Blanchard, 1982; Hoy \& Miskel, 1996). Lastly, Mintzberg developed another power typology that emphasizes the control over a resource, skill, or information. Four systems of power exist: system of authority, system of ideology, system of expertise, and system of politics. Hoy \& Miskel (1996) compare these models and notes that only Mintzberg's typology includes internal political power. They also stress the importance of various perspectives on power. Structural, cultural, individual, and political perspectives look at legitimate authority, informal power, expertise, and illegitimate power, respectively (Hoy \& Miskel, 1996).

These typologies prompted further research in the leader's use of power, considerations, and consequences. Yukl summarized research in this area. The use of personal forms of power, expert and referent, are likely to result in greater follower satisfaction and performance. In contrast, coercive power is negatively correlated to performance. Legitimate power is not correlated to performance and research results on reward power are inconsistent (Bensimon, 1989; Hoy \& Miskel, 1986).

The concept of power is an important theme in leadership research. It can be conceptualized in several ways. Power may be a separate construct, either a dependent or independent variable, or it may be part of the dynamics of leadership and influence (Bowditch \& Buono, 1985). Early research primarily emphasized the ways in which leaders used power to influence subordinates 
in a one-direction approach. However, social exchange theories consider the mutual and reciprocal relationships that exist in organizations and between persons in various positions of authority. Leadership is a much more dynamic process where leaders accumulate power, which is mediated by a variety of factors such as followers' expectations and authority acceptance.

The leader-follower relationship, which is central to social exchange theory, is also a key element in understanding another power and influence theory: transactional leadership. This theory views the leader-follower relationship as a bargaining process between leaders and followers. Economic, psychological or political assets may be exchanged, which shifts group or individual autonomy and leader power. Moderating variables in this process include perceptions of fairness, honesty, trust, and commitment. Transactional leadership assists followers in meeting their needs. Leaders accept the existing organizational culture and norms (Bensimon, 1989; Hoy \& Miskel, 1986; Van Eron \& Burke in Clark et al., 1992, pp. 149-166). Recent research in the area of leader-follower relationships have explored the strategies used by charismatic leaders to effect social change (Conger, 1999; Hunt, 1999; Fiol, 1999).

Another power and influence theory that extended the ideas of transactional leadership is transformational leadership. Although transactional and transformational leadership share some common elements, they have distinct differences. Transformational leadership emerged in the 1980 's as a way to describe the ways in which leaders may significantly influence culture and commitment. Terms such as shared leadership, empowerment, coaching, teamwork, and participative decision-making surfaced from these theories and research studies. Burns' theory, based on political leadership, describes transformational leader strategies that appeal to the higher moral values of followers. Burns contends that leaders at any level in an organization may bring about positive changes by encouraging others to act out of idealistic, selfless motives such 
as humanitarianism. Bass further defined transformational leadership as the effect a leader has on followers. Leaders transform followers by activating their higher level needs and stimulating an increase in certain positive organizational attributes. This may include commitment, trust, respect, involvement, and productivity. Transformational leadership causes lasting change in organizational structure and management systems, communication, and culture (Clegg \& Hardy, 1999; Conger, 1999; Hoy \& Miskel, 1986; Hunt, 1999; Siegrist, 1999; Van Eron \& Burke in Clark et al., 1992, pp. 149-166; Yukl \& Van Fleet in Dunnette \& Hough, 1990, pp. 173-179).

An overlapping, but more narrowly defined theory is charismatic leadership. The term "charismatic" was used by Weber and Blau and Scott. It describes a certain type of authority that stems from personal appeal and a common value commitment between leaders and followers (Clegg \& Hardy, 1999; Hoy \& Miskel, 1986). House identified charismatic behavior and favorable conditions under which this type of leadership may flourish (House, 1971).

Charismatic leader behaviors may include: (1) manage impressions to maintain follower confidence, (2) articulate an appealing vision, (3) communicate and clarify high expectations, (4) build confidence in followers' abilities, and (5) set an example of model behaviors. In addition to House's theory, Conger (1999) and Kanungo's research and theory are based on many of the same leader attributes as well as situational variables. Research has generally supported the validity of both transformational and charismatic theories. However, such leaders usually emerge in times of organizational crisis or rapid change. The emergence of charismatic leaders is also more likely to occur in loosely structured organizations with well-educated members (Bensimon, 1989; Sashkin, Rosenbach, Deal, \& Peterson in Clark et al., 1992, pp. 131-146; Yukl \& Van Fleet in Dunnette \& Hough, 1990, pp. 173-175). There are many aspects of charismatic leadership that are not fully understood. As one researcher describes this field of research, "we 
are in the Iron Age in terms of our understanding of both charismatic and transformational leadership" (Conger, 1999).

Power and influence theories represent a change in theoretical paradigms. Concepts underlying these theories go beyond "traditional" or sometimes ignored aspects of organizational leadership and behavior. Culture, symbolism, and politics are inherent in every organization and these dynamic and abstract concepts are important contributions to leadership theories. When rational solutions or explanations fail to illustrate what is happening in an organizational situation, it is likely that these factors are the reason. Bolman and Deal's political frame is based on the same assumptions as the power typologies and research. While the political frame does not embrace any one theory, leaders who adopt this frame view the organization in terms of different special interest groups. Leaders attempt to solve problems by analyzing preferences, designing alternatives, and influencing groups and individuals to support the leader's idea. The leader is a mediator and negotiator (Bensimon, 1989; Bensimon et al., 1989; Bolman \& Deal, 1997).

Bolman and Deal's symbolic frame is directly related to power and influence theories as well. The symbolic frame is best known as "the way we do things around here" or patterns of shared perceptions, thoughts, and feelings that people in organizations use to adapt and explain organizational events (Bolman \& Deal, 1995; Bolman \& Deal, 1997). Symbolism is widely recognized as a vital part of the context of leadership (Tierney, 1989). Transformational theories describe the process in which leaders are expected to create a positive culture, communicate a clear vision, and promote inspirational values to followers. Charismatic leaders possess these types of personal qualities and skills. Bolman and Deal's symbolic frame is consistent with these theories in that leaders who operate within this frame use interpretive strategies in influencing 
culture and symbolism (Bensimon, 1989; Bensimon et al., 1989; Birnbaum, 1989; Bolman \& Deal, 1992, 1994, 1997, 1999; Neumann, 1989; Tierney, 1989). Bolman and Deal emphasize the importance of certain assumptions within this frame. Organizational events (e.g. meetings, plans, communications, and appearances) are expressions of culture and power. Leaders can create meaning and discover a spirit of high performance through these opportunities (Bolman \& Deal, 1995; Bolman \& Deal, 1997). A study of higher education presidents found that about 22\% espoused symbolic leadership theories and $87 \%$ described their personal leadership theories in terms of power and influence (Birnbaum, 1989). Bensimon (1989) contends that symbolic leadership deserves more attention because it is compatible with the characteristics of academic organizations. Slater (1994) concurs, and calls for symbolic leadership to restore and revitalize the alienation and "crises of meaning" found in education.

All four frames - structural, human resource, political, and symbolic - relate to leadership and higher education institutions. The images of "ivory towers" and bureaucratic systems fit with the structural frame. Top down structures, such as those that exist in colleges and universities, often emphasize central authority. This authority may use rational, administrative procedures to solve problems. The use of business strategies to improve efficiency (e.g. management by objectives, goal setting) is typical of the structural frame perspective. Bensimon et al. (1989) report that bureaucratic control is prevalent in private and community colleges. They also assert that human resource skills were rated less important than rational skills and heroic, symbolic leadership skills by community college presidents.

The human resource frame is also evident since colleges and universities are communities of scholars. A professional, collegial atmosphere is a deeply held value manifested in systems of shared governance, consensus, appreciation of diversity, and academic freedom. The university 
is, undoubtedly, a political system. The political frame is useful in seeing how power and resources are distributed. In a loosely organized system, leaders must rely on skills to build support networks, facilitate common agendas, and negotiate distribution of limited funding or resources, which are responsibilities critical to higher education administrators. Lastly, higher education leaders may use the symbolic frame to shape the organizational culture and values. The four frames of leadership - structural, human resource, political, and symbolic - may provide meaningful and useful perspectives in leading and managing higher education organizations. Table 4 (p.66) outlines Bolman and Deal's leadership frames and descriptors associated with each frame.

\section{Research on the Four Leadership Frames}

Since Bolman and Deal first developed the leadership frame model, studies have been conducted to further understand which frames are used, how leaders use each frame, and what results from leaders' abilities to use leadership frames. Both qualitative and quantitative studies using this framework have been conducted. Qualitative research employed the methods of interviews (both leader and colleague) and oral reports of critical incidents. A series of qualitative studies with higher education leaders demonstrate that Bolman and Deal's framework can be broadly applied in research. Birnbaum, Neumann, Bensimon, and Tierney conducted interviews with college presidents with each author using a different interpretive lens (Bensimon, 1989; Birnbaum, 1989; Neumann, 1989; Tierney, 1989). For example, Tierney used the interview data to focus only on the symbolism used by presidents. Results show the complex reality of leadership and the fact that it cannot be boiled down to a simple, objective set of results or recommendations. These studies reveal the wide variety of models, theories, strategies, 
definitions, and symbols of leadership that may be found through qualitative research (Chaffee, 1989).

Another study of college presidents' images of their leadership roles found a diversity of presidential realities (Neumann \& Bensimon, 1990). The researchers portray the data in four presidential types, A, B, C, and D, according to presidents' target of attention, mode of action, and relatedness to the institution. These classifications were made to assist others in fully appreciating the richness of leadership experiences and situations and not to simplify leaders into neat categories. Leaders' personally constructed theories of leadership are more complex than any typology could completely capture. This is why several researchers caution against oversimplified categories of leadership and singular research perspectives (Chaffee, 1989; Neumann \& Bensimon, 1990). There appears to be strong support for diverse approaches and research techniques in studying leadership frames of higher education leaders.

There are many studies reporting a consistent pattern of human resource frame as the predominant frame choice. Bolman and Deal's research (2001) using a multisector sample of managers in business and education resulted in very close structural and human resource scores on their survey instrument. In a study by Bolman and Deal (1992), two groups of school principals from Florida and Singapore revealed a difference in frame choice in explaining critical incidents. American principals primarily used the human resource frame and secondarily used the structural frame, and principals from Singapore had a reverse frame choice pattern. The Leadership Orientations (Self) Survey was used to collect the data. It is also interesting to note that despite obvious cultural differences, there are not wide variations between leadership orientations of leaders and managers from different countries. Other studies of principals and 
school administrators found the human resource frame as the dominant frame (Davis, 1996; Durocher, 1995; Rivers, 1996).

Studies related to higher education leaders follow the same trend. A study of perceptions of department chairs by 172 faculty members indicated that chairs predominantly used the human resource frame (Mathis, 1999). Furthermore, faculty rated their level of job satisfaction and this was compared to chairs' leadership orientations. Faculty with chairs scoring high on the symbolic frame expressed higher intrinsic and overall job satisfaction. Another finding in Mathis' (1999) study was that symbolic and human resource frames were superior to the structural frame in terms of extrinsic job satisfaction. Using the same instruments, Crist (1999) gathered data from 235 chief academic officers regarding their job satisfaction and their perceptions of the leadership orientations of the institution president. Results underscored Mathis' conclusion that differences in extrinsic and overall job satisfaction were most often impacted by presidents' use of the human resource frame alone or paired with another frame.

Another study of nursing department chairs rated by 253 faculty on the Bolman and Deal instrument supports the predominant use of the human resource frame, followed by the structural, symbolic, and political frames (Mosser, 2000). This study also found that leadership orientations affected the organizational climate of the department particularly regarding consideration, intimacy, and production emphasis.

Cantu (1997) sampled 426 academic deans from across the United States, mirroring the same frame choice pattern. Other populations within educational institutions show similar results. The human resource frame was most utilized by student personnel professionals (McClellan-Holt, 2000), key administrators (Carter, 1995), dental and medical school deans (Flaer, 1998), and campus safety directors (Wolf, 1998). Unlike most other studies, Chang 
(2004) found that department chairs in colleges of education most frequently used the structural frame. There appears to be some variations among different environments. Kelly (1997) compared leadership orientations of business and industry executives with higher education administrators and found no statistically significant differences in mean scores on the leadership frames. In summary, leadership orientations research of higher education leaders using the Bolman and Deal survey consistently show that the human resource frame is the most frequently used frame. This is consistent with research of leaders in other types of organizations.

A major aspect of the multiple frame leadership model is flexibility in reframing organizational situations using multiple perspectives. Higher education scholars agree that a leader's ability to use multiple frames is a strong indicator of effectiveness and perceived effectiveness (Bedore, 1998; Bensimon, 1989; Bensimon et al., 1989; Birnbaum, 1988; Birnbaum, 1989; Bolman \& Deal, 1984, 1992, 1994, 1997, 1999; Chaffee, 1989; Neumann, 1989; Neumann \& Bensimon, 1989). Many studies analyzed leadership orientation patterns according to single, paired and multiple frame use. The trends in such studies vary in their percentages of leaders exhibiting different combinations of frames. Using the Leadership Orientations (Other) Survey, mean scores, studies have revealed different results. Crist (1999) found $7.2,21.8,36.5,25.9$ and $8.5 \%$ of leaders used no frame, single frame, paired frame, three frames, and four frames, respectively. Mosser (2000) documented 39.5, 16.6, 12.7, 9.2, and $22.1 \%$ of leaders used no frame, single frame, paired frame, three frames, and four frames, respectively. Chang (2004) found that the use of no frame style, single frame style, paired frame style, and multiple frame style was $56.8,14.8,13.6$, and $14.8 \%$ respectively. Another study reported $32 \%$ used no leadership frame, $11 \%$ used one frame, and 36\% were classified as using four frames (Mathis, 1999). Bolman and Deal's (1992) study with Florida principals found that 
$16,58,19$, and $6 \%$ used one, two, three, and four frames respectively. Using interview data, Bensimon's (1989b) sample of higher education presidents showed that 41,34 , and $25 \%$ of these leaders used single, paired, or multiple frames, respectively. Multi-frame orientations were more prevalent among presidents of large universities than colleges.

Leadership frame research also shows how leader characteristics such as tenure or experience may affect orientations. There is general consensus that experienced leaders are more likely to use multiple frames compared to newer leaders. For example, multi-frame perspectives were evident almost exclusively in experienced presidents and those who had been president of one or more institutions (Bensimon, 1989). This, Bensimon concludes, may suggest that the use of complex leadership approaches is developmental. The manifestation of diverse leadership strategies may be a direct result of accumulated experience and the presidents' ability to adapt to constantly changing environments. Neumann (1989) concurs with this view when contrasting old presidents' initial and current strategies. Over time, the presidents moved from a linear (structural, goal-oriented) strategy style to more adaptive (responsive and accommodating the environment) and interpretive (shaping the values and perceptions) strategies. One study by Harlow (1994) disputes the view that years of experience directly affects the number of frames used. However, the majority of research demonstrates that there is a significant difference between experience and multiple frame leadership.

The previous research cited by Bensimon (1989) and Neumann (1989) shows that as presidents gained experience, their leadership strategies became more sophisticated and more multi-frame. Interestingly, studies suggest that while multiple frame use appears to increase with leadership experience, there is a more varied pattern with respect to age and the specific type of leadership frame used. Kelly’s (1997) research found no statistically significant pattern of frame 
use and years of experience. The study by McClelland-Holt (2000) found similar results. There is also some evidence, although not always statistically significant, that more experienced leaders use the political frame to a greater extent than less experienced leaders (Bolman \& Deal, 1999; Cantu, 1997; Cote, 1999; Frick, 1996). Research by Kelly (1997) and Wolf (1998) shows a statistically significant difference between age and use of the political frame.

In addition to age and tenure, gender has been studied as a variable in leadership frame research. Studies do not support any stereotypes or notions that men and women lead differently. Bolman and Deal (1992) give evidence that men and women generally are more alike than different. Regarding their leadership frame, the American women in Bolman and Deal's sample rated themselves significantly lower on the political frame. Compared to men, women were rated by their colleagues higher on every frame. The researchers comment that results suggest women are judged by different expectations than men. Others rated women as more effective when they scored higher on the structural frame items. Conversely, men were evaluated as effective leaders when they used the human resource and political frames. A study of educational leaders using the Bolman and Deal instrument found no significant differences between men and women with respect to their leadership characteristics and perceived effectiveness (Thompson, 2000). In contrast, Cote (1999) found a significant relationship between gender and frame among school principals, as did Frick's (1996) study of school superintendents. It is important to note the variations in leadership frame research. Not all studies looked at the issue of gender and different methodologies were used in assessing the leadership frame. Because of these variations in research, gender may be an important variable that affects the leadership frame use and how others perceive the leader. 
A literature search resulted in one research study pertaining to Bolman and Deal's model and the specific population of extension leaders. Tennessee Agricultural Extension Service home economists ( $n=166 ; 98.9 \%$ female) were surveyed using the Leadership Orientations (Self) Survey in addition to Petty's instrument on work ethic (Hollingsworth, 1995). Mean scores on leadership frames were 4.15 human resource, 3.75 structural, 3.58 symbolic, and 3.35 political. Work ethic was significantly related to leadership orientation and predicted the following variations in leadership frame orientations: political $48 \%$; symbolic $40 \%$; structural $38 \%$; and human relations 35\%. Survey scores from Hollingsworth's study provide a valuable point of comparison because of several common elements in this study of WVUES County Program Coordinators.

County extension faculty are known in their communities as leaders. County Program Coordinators develop and manage fiscal and human resources, coordinate programs, and communicate with all levels of constituents and stakeholders. They must be strong leaders in order to effectively perform these responsibilities. Leadership research affirms that the ability to adapt, interpret and reframe day-to-day situations using different frames or viewpoints is a key indicator of effectiveness. This asset is clearly tied to perceptions of leadership effectiveness by others. However, there is no current information available on the leadership orientations of coordinators. There is a lack of research related to county extension leaders using Bolman and Deal's leadership model and frame analysis.

\section{Summary}

A review of the relevant literature on leadership reveals that this is an area of importance to higher education, extension, and other types of organizations. The gap in the literature relating to the leadership abilities extension leaders reflects a need for studies to expand the body of 
knowledge. Studying extension leadership issues provides an understanding of this specific organization, its leaders, and whether such issues are consistent with the current literature. In addition to bridging the research gap, studies may provide guidance for administrative and leadership practices of the extension organization. 


\section{Chapter 3}

\section{Method}

This chapter describes the procedural aspects of the study. Topics included are the participants, survey instruments, and the analytical methods used in data analysis. The following research questions guide the methods used in the study:

1. Which leadership styles - no frame style, single frame style, paired frame style, or multiple frame style - do West Virginia University Extension Service County Program Coordinators perceive themselves to use as measured by the Leadership Orientations (Self) Survey?

2. Are there statistically significant relationships between County Program Coordinator leadership styles as measured by the Leadership Orientations (Self) Survey and the selected background characteristics of gender, years of extension experience, program center assignment, and number of office staff?

3. Which leadership styles - no frame style, single frame style, paired frame style or multiple frame style - do County Extension Service Committee members perceive the County Program Coordinator in their county to use as measured by the Leadership Orientations (Other) Survey? How do these results based on County Extension Service Committee member (other) perceptions compare with the results of County Program Coordinator (self) perceptions (Research Question 1)?

4. Are there statistically significant relationships between County Program Coordinator leadership styles as identified by County Extension Service Committee members and County Program Coordinator leadership styles as identified by coordinators?

5. What are the critical leadership incidents as described by County Program Coordinators, 
as measured by the Leadership Orientations (Self) Survey? How do these descriptions compare to the leadership styles?

Table 1 provides an overview of the research questions, variables, and analysis. 
Table 1

Research Questions, Variables, and Analysis

Research Question 1:

Which leadership styles - no frame style, single frame style, paired frame style, or multiple frame style - do West Virginia University Extension Service County Program Coordinators perceive themselves to use as measured by the Leadership Orientations (Self) Survey?

\section{Dependent Variables:}

4 Leadership Frames

$\underline{\text { Frame Scores }}$

Structural frame

Human resource frame

Political frame

Symbolic frame

$\underline{\text { Leadership Styles }}$

No frame

Single frame

Paired frame

Multiple frame

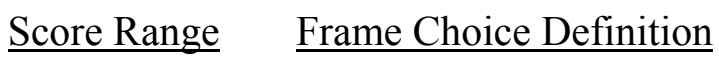

$$
8-40
$$$$
8-40
$$$$
8-40
$$

$8-40$
Mean $\geq 4.0$

Mean $\geq 4.0$

Mean $\geq 4.0$

Mean $\geq 4.0$ $\underline{\text { Analysis }}$

Frequencies for no

frame style, single

frame style, paired

frame style, and

multiple frame

no frame scores $\geq 4.0 \quad$ style

one frame score $\geq 4.0$

two frame scores $\geq 4.0$

three-four frame scores $\geq 4.0$ 
Table 1 (Continued)

Research Questions, Variables, and Analysis

\section{Research Question 2:}

Are there statistically significant relationships between County Program Coordinator leadership styles as measured by the Leadership Orientations (Self) Survey and selected background characteristics of gender, years of extension experience, program center assignment, and number of office staff?

\begin{tabular}{|c|c|c|}
\hline Independent Variables: & & Analysis \\
\hline Gender & & Pearson product-moment \\
\hline Years of extension experience & & correlations computed with \\
\hline Program center assignment & & 4 independent variables \\
\hline Number of office staff & & (background \\
\hline Dependent Variables: & & characteristics) and each \\
\hline$\underline{\text { Leadership Frame Scores }}$ & $\underline{\text { Score Range }}$ & dependent variable \\
\hline Structural frame & $8-40$ & (leadership frame scores \\
\hline Human resource frame & $8-40$ & and leadership styles). \\
\hline Political frame & $8-40$ & \\
\hline Symbolic frame & $8-40$ & \\
\hline \multicolumn{3}{|l|}{$\underline{\text { Leadership Styles }}$} \\
\hline No frame & no frame scores $\geq 4.0$ & \\
\hline Single frame & one frame score $\geq 4.0$ & \\
\hline Paired frame & two frame scores $\geq 4.0$ & \\
\hline Multiple frame & three-four frame scores $\geq 4.0$ & \\
\hline
\end{tabular}


Table 1 (Continued)

Research Questions, Variables and Analysis

\section{Research Question 3:}

Which leadership styles - no frame style, single frame style, paired frame style, or multiple frame style - do County Extension Service Committee members perceive the County

Program Coordinator in their county to use as measured by the Leadership Orientations (Other) Survey? How do these results based on County Extension Service Committee member (other) perceptions compare with the results of County Program Coordinator (self) perceptions (Research Question 1)?

\begin{tabular}{lcl}
\hline $\begin{array}{l}\text { Frame Scores in (Other) Survey } \\
\text { Structural frame }\end{array}$ & $\underline{\text { Definition }}$ & \multicolumn{1}{c}{ Analysis } \\
Human resource frame & Mean $>4.0$ & A. Mean frequencies computed for no \\
Political frame & frame style, single frame style, paired \\
Symbolic frame & frame style, and multiple frame style \\
$\begin{array}{l}\text { Leadership Styles from (Self) } \\
\text { and Composite (Other) Surveys }\end{array}$ & from (other) surveys. \\
$\begin{array}{l}\text { No frame style } \\
\text { Single frame style }\end{array}$ & Bean $>4.0$ & B. Frequencies computed for no frame style, \\
Paired frame style & & single frame style, paired frame style, and \\
Multiple frame style
\end{tabular}


Table 1 (Continued)

Research Questions, Variables, and Analysis

\section{Research Question 4:}

Are there statistically significant relationships between County Program Coordinator leadership styles as identified by County Extension Service Committee members and County

Program Coordinators leadership styles as identified by the coordinators?

Independent Variables:

$\underline{\text { Leadership Styles (Other) }}$

$\underline{\text { Analysis }}$

No frame

A. Pearson product-moment correlations computed

Single frame between coordinators' self-identified leadership

Paired frame style and mean leadership style identified by

Multiple frame County Extension Service Committee members as

Dependent Variables: in Research Question 3.

$\underline{\text { Leadership Styles (Self) }}$

No frame

B. Pearson product-moment correlations computed

Single frame between matched coordinator and committee

Paired frame member leadership style groups.

Multiple frame 
Table 1 (Continued)

Research Questions, Variables, and Analysis

\section{Research Question 5:}

What are the critical leadership incidents as described by County Program Coordinators as measured by the Leadership Orientations (Self) Survey? How do these descriptions compare to the leadership styles?

Variables: Critical Incidents and Leadership Styles

Described in Leadership Orientations (Self) Survey

$\underline{\text { Section III }}$

Greatest accomplishments

Leadership skills or behaviors to accomplish

Greatest challenge

Leadership skills or behaviors to address challenge $\underline{\text { Analysis }}$

Qualitative analysis techniques used to aggregate and interpret the Survey Section III data.

(See Table 3.) 


\section{Participants}

There were two groups of participants in this study. First, there were 55 County Program Coordinators employed by the WVUES. As described in Chapter 1, the general staffing pattern in West Virginia was one County Program Coordinator for each county. Fourteen counties had coordinator vacancies or coordinators with less than a year of experience as a coordinator in the county. These counties were not included in the study. Additionally, six County Program Coordinators who were currently supervised by the author were not included as participants to avoid any conflict of interest. The total sample of this group consisted of 35 people, or $62 \%$ of the entire County Program Coordinator population of 53 people. Participant code numbers were assigned to protect their identity. Responses were coded with numbers for subsequent use in the data analysis. Identities were not available thereafter. Approval by the West Virginia University Institutional Review Board for the Protection of Human Subjects was obtained, and ethical procedures for protection of human participants were observed.

Participant demographics may be described according to gender, program center assignment, years of experience and office staffing patterns. Of the 35 potential participants, 25 were male and 10 were female. The academic backgrounds of extension faculty varied from agricultural sciences, family and consumer sciences, and education to other diverse fields such as social work, communications, and business. One had a doctoral degree, thirty two had master's degrees and two had bachelor's degrees.

Each extension faculty member is assigned to one of two program centers to give them a support base primarily related to their program responsibilities and secondarily related to their subject matter background. At the time of the study, the two program centers were: (1) 
Agriculture, Natural Resources, and Community Development and; (2) 4-H and Youth, Family, and Adult Development.

The number of years of WVUES experience among County Program Coordinators ranged from less than a year to 36 years. Participants were divided into three groups according to their years of extension experience. These groups were: (a) less than 10 years, (b) 10-20 years, and (c) more than 20 years. Each group constituted approximately one third of the participant sample. Since the complexity of office staffing patterns may have a direct impact on the leadership demands on County Program Coordinators, these data were included in the demographic variables of the study. A great deal of diversity exists among county offices in terms of staffing patterns. They range from a minimum of one clerical/support staff and one coordinator/faculty member to a maximum of three clerical staff, three faculty members (including the coordinator), and several program staff. Approximately $20 \%$ of counties have formal faculty assignments in adjacent counties to contribute to program efforts in addition to the county in which they are based. This multi-county configuration assists counties by adding program resources in a variety of subject matter areas. The coordinator responsibilities for budget development, program coordination, and communication may become increasingly complicated when situations involve several faculty with different and diverse assignments. In light of the variations that exist among counties, each coordinator is placed in one of the following staffing categories: (a) one full-time faculty plus clerical/support staff, (b) two full-time faculty plus clerical/support staff, and (c) three full-time faculty plus clerical/support staff. At the time of the study, the total number of counties with only one faculty was 22 , or $40 \%$. There were 21 counties, or $38 \%$, with two faculty. Twelve counties, or $22 \%$, had three faculty. 
A second group of study participants was County Extension Service Committee members. Eight members serve on each of the 55 counties' County Extension Service Committees in West Virginia. The function and makeup of the committees are mandated by West Virginia State Code (West Virginia Agricultural Laws, 1915, 1990). The committees' purposes are:

1. To enter into a memorandum of agreement with the Cooperative Extension Service of West Virginia University for the employment of county cooperative extension workers. 2. To prepare a memorandum of agreement with the county commission and with the county board of education for their financial support of extension work.

3. To give guidance and assistance in the development of the county Cooperative Extension Service program and in the preparation of the annual plan of work for the county (West Virginia Agricultural Laws, 1915, 1990).

Each committee has up to eight members approved by the President of West Virginia University and appointed by the West Virginia University Board of Governors. Members may serve for three years or more. A committee is composed of the county president of the Farm Bureau, county president of the Community Educational Outreach Service, county president of the 4-H Leaders' Association, a representative of the County Commission, a Board of Education member, a county Grange representative, and two county residents. Committee members who represent a constituency group serve for the length of time as determined by their respective group. The coordinator has the responsibility to work closely with the committee in several ways. They ensure that appropriate committee nominations are forwarded to the university for presidential approval of the appointments. Coordinators assist the committee as needed in securing annual budget and personnel memoranda. The committee also makes a decision each year about the continuation of faculty and support staff assignments in the county. Coordinators 
serve as the communication link with WVUES administrators, faculty, and staff. In this capacity, they keep all members abreast of program plans and accomplishments and facilitate the resolution of budget, staffing, or programmatic problems that may arise.

There is a maximum of 440 County Extension Service Committee member appointments statewide (55 counties x 8 members on each committee). For the purposes of this study, only members who served on the committee for more than one year were included. More experienced members have greater knowledge about the WVUES and the coordinator than the less experienced members. Therefore, these participants may be able to respond more knowledgeably to questions about the leadership skills and behaviors of the coordinator. Additionally, since committee members are often appointed for three-year terms, there is a potential of one-third turnover each year. However, representative organizations often re-elect the same president or designee. Since it is not unusual for members to be appointed for additional terms, an attrition rate of one third each year is unlikely. Approximately 260 County Extension Service Committee members were selected to participate in the study.

Ethical procedures for protection of human participants were observed. Approval of the West Virginia University Institutional Review Board for the Protection of Human Subjects was obtained. Participant code numbers were assigned to protect the identity of coordinators and committee members. Survey responses were coded with numbers for subsequent use, and all identities were kept confidential. Appendix G includes the documentation of approval by the Institutional Review Board. 


\section{Data Collection}

Data were collected via surveys adapted from the Bolman and Deal Leadership Orientations (Self) Survey and Leadership Orientations (Other) Survey instruments and included in Appendix B (Bolman and Deal, 1991). Dr. Lee Bolman granted permission for use of the instrument in this study and a copy of this authorization is provided in Appendix A. The "self" version of the instrument has leaders rate themselves, and the "other" version has colleagues or others rate the leaders.

This study used the Leadership Orientations (Self) Survey with coordinators and the Leadership Orientations (Other) Survey with members of their committee. There were several reasons that County Extension Service Committee members were asked to participate in this study. First, gathering data on leadership orientation from two sources helps ensure objectivity and accuracy in analyzing and coding the data. Second, the coordinator has no true peer within the county office or work unit. They have faculty peers, but no coordinator peers in their county. The closest coordinator peer would be in an adjacent county. Coordinator peers may not have enough information (e.g. direct observation, client feedback) on which to rate another County Program Coordinator. A coordinator in one county may not accurately understand the unique County Program Coordinator leadership context of another individual county. These difficulties make it impossible to consistently define and obtain peer survey data. In lieu of colleague ratings, committee members were surveyed. While they are not internal to the extension organization, as would be a peer group, committee members are knowledgeable about the organizational and office operations as well as the leadership behaviors and skills of county extension faculty. Lastly, ratings of coordinators by community leaders and comparisons with coordinators self-ratings may provide insightful data. 
The structure of the Bolman and Deal instrument is shown in Table 2. As noted there, each of the four leadership frames (structural, human resource, political, symbolic) includes eight items. The adapted survey contains two parts. Section I has 32 items that the participant selfrates how often each item is true. For example, item number one asks, "Think very clearly and logically." Participant responses use a five-point Likert scale of 1 (Never), 2 (Occasionally), 3 (Sometimes), 4 (Often), and 5 (Always). There are eight items for each of the four leadership frames. Scores for each frame in this section range from a possible low of 8 to a high of 40. Section II has six questions for leaders to rank their strongest skills, abilities, sources of success, others' perceptions of their leadership, most important leadership trait, and overall description. Each question has four choices that pertain to each of the four leadership frames. Participants rank each from 1 (least like them) to 4 (most like them). Scores for each frame in this section range from 8 to 40 . This section provides more distinction between frames because the question format does not permit someone to self-rate high on everything (which is possible in Section I).

Relevant to Research Question 5, another section was added to the instrument to collect data on critical incidents of leadership. The survey is in Appendix B. This is only collected from the coordinators and not the committee members. In this section, four open-ended questions ask for descriptive information on significant accomplishments and challenges as well as the leader behaviors and skills they used to address them. 
Table 2

The Structure of the Bolman \& Deal Leadership Orientations (Self) and (Other) Surveys

\begin{tabular}{lcc}
\hline Survey Section and Frame & Survey Items & Reliability (Coefficient Alpha) \\
\hline$\underline{\text { Section I: }}$ & $1,5,9,13,17,21,25,29$ & $r=.920(1)$ \\
Structural frame & $2,6,10,14,18,22,26,30$ & $r=.931(2)$ \\
Human resource frame & $3,7,11,15,19,23,27,31$ & $r=.913(3)$ \\
Political frame & $4,8,12,16,20,24,28,32$ & $r=.931(4)$ \\
&
\end{tabular}

Section II:

Structural frame

1a, 2a, 3a, 4a, 5a, 6a

$r=.841(5)$

Human resource frame

$1 b, 2 b, 3 b, 4 b, 5 b, 6 b$

$r=.843(6)$

Political frame

$1 c, 2 c, 3 c, 4 c, 5 c, 6 c$

$r_{-}=.799(7)$

Symbolic frame

$1 \mathrm{~d}, 2 \mathrm{~d}, 3 \mathrm{~d}, 4 \mathrm{~d}, 5 \mathrm{~d}, 6 \mathrm{~d}$

$r=.842(8)$

Note. (1) Reliability coefficients reported for 1,309 peers

(2) Reliability coefficients reported for 1,331 peers

(3) Reliability coefficients reported for 1,268 peers

(4) Reliability coefficients reported for 1,315 peers

(5) Reliability coefficients reported for 1,229 peers

(6) Reliability coefficients reported for 1,233 peers

(7) Reliability coefficients reported for 1,218 peers

(8) Reliability coefficients reported for 1,221 peers

From Bolman, L. (2001). http://www.bsbpa.umkc.edu/classes/bolman/Default.htm 
Survey reliability has been established through research by Bolman and Deal (http://www.bsbpa.umkc.edu/classes/bolman, 2001). Statistical data were obtained for each set of leadership frame items. Coefficient alpha reliabilities were $.920, .931, .913$, and .931 for the structural, human resource, political, and symbolic frames. However, it should be noted that these reliabilities were based on peer or colleague ratings for a multi-sector sample of managers in business and education and not based on self ratings. Bolman (2001) commented, "Research has generally found that the validity of self-ratings of leadership is generally low, so there's considerable advantage in getting colleague ratings." The phenomenon of discrepancies between self and other ratings is prevalent in the research literature (Clark \& Clark in Clark et al., 1992). Other references indicate that the differences in self and other rater scores vary from one frame to another. Leader ratings from subordinates (as opposed to colleagues) have greater deviations and are more dispersed. However, these differences are not interpreted as significant flaws in research or instrument design, but seem to be interpreted as evidence of the multiple realities of leadership (Bensimon et al., 1989; Bolman \& Deal, 1999; Neumann \& Bensimon, 1990). Ratings from stakeholders, as used this study, have not been documented in the literature.

\section{Procedure}

Pre-notice letters were sent to each of the participants by the Director of Extension. The letters endorsed the study and encouraged participation. Following the initial letter, surveys were sent. The Leadership Orientations (Self) Survey was e-mailed as an attachment to each County Program Coordinator in the sample. The e-mail message explained the purpose of the study, requested their participation, and assured them of confidential procedures. Participants were asked to complete and return the survey via e-mail within two weeks. The e-mail cover letter is 
in Appendix E. A response rate of 35 surveys was desired. Follow-up procedures were followed, as recommended by Dillman (2000), to assure an optimal response rate.

To obtain the data from the second group of study participants, a Leadership Orientations (Other) Survey was mailed to each County Extension Service Committee member who served for at least a year. An accompanying cover letter explained the purpose of the study and benefits of their participation. The cover letter is in Appendix F. With 240 surveys sent, a response rate of $70 \%$ or 168 completed surveys was desired. Follow-up procedures were followed with this group, according to Dillman's (2000) research-based approach.

\section{Data Analysis}

To answer Research Question 1, the Leadership Orientations (Self) Survey scores and mean scores were computed for each leadership frame. Using the scoring guidelines in Table 3, individual leaders' frame choice(s) and resulting predominant leadership style(s) were identified. Leadership frame choice is operationally defined as a mean rating of 4.0 or higher for the items of a given leadership frame in Section I. Section I and Section II of the survey provide two sets of scores which can be cross-checked. For example, a participant scoring 34 (mean of 4.25 per item) on the eight structural frame items in Section I would be expected to similarly exhibit a score of 20.4 (mean of 3.4 per item) for the six items measuring the structural frame in Section II. Frequency distributions of individual scores for each leadership frame reveal leadership orientation patterns for the entire group of coordinators as well as subgroups. Table 3 outlines the scoring guidelines used in the analysis.

To answer Research Question 2, statistics were computed using the Statistical Product and Service Solutions (SPSS) software. Potential differences among participants were examined using Pearson's product-moment correlations computed for each of the independent variables. 
These variables were gender, years of extension experience, program center assignment, and office staffing pattern. For example, using the independent variable of years of extension experience (participants were categorized according to less than 10 years, 10-20 years, and over 20 years), the correlation analysis included four dependent variable scores, one for each leadership frame measured. Table 3 outlines the scoring guidelines used in the analysis.

To answer Research Question 3, statistics were computed using the Statistical Product and Service Solutions (SPSS) software. The variables were the four leadership frames as measured by Leadership Orientations (Other) Survey. Analyses included descriptive statistics of frequencies, means, and standard deviations. Table 3 outlines the scoring guidelines used in the analysis.

Research Question 4 compared coordinators' leadership styles, as identified by the two participant groups, coordinators and committee members. Dependent variables were the leadership styles from the Leadership Orientations (Self) Survey. Independent variables were the leadership styles from the Leadership Orientations (Other) Survey. Descriptive statistics and correlations were computed to determine if there were any statistically significant relationships between the two sources of ratings. A mean composite score of committee members were the basis of comparison with the mean individual scores from the County Program Coordinator survey data.

Question 5 involved qualitative techniques to describe critical leadership incidents in terms of the four leadership frames and leadership practices. The qualitative techniques were methodological triangulation and investigator triangulation (Creswell, 1994; Patton, 1990). Methodological triangulation involved the use of multiple methods to study a single problem. In this study, open-ended questions in Section III of the survey provided a secondary source of data 
on leadership style. Data from Section III of the Leadership Orientations (Self) Survey of all coordinators were analyzed and interpreted according to Table 4 descriptions of each of the frames. The descriptive illustrations of each leadership frame were derived from the literature (Bolman \& Deal, 1992; Bensimon \& Neumann, 1990; Bensimon, Neumann, \& Birnbaum, 1989). Two independent field experts were selected to evaluate and analyze the qualitative data according to the given descriptors. The field experts were selected based on their thorough understanding of WVUES and qualitative research content analysis. This step in qualitative research, investigator triangulation, is shown to help guard against researcher bias and misinterpretation (Creswell, 1994; Patton, 1990). 
Table 3

Survey Scoring Guidelines

\begin{tabular}{lccc}
\hline Leadership Frame & \multicolumn{1}{c}{ Survey Items } & Score & Frame Choice \\
& & Range & Definitions \\
\hline $\begin{array}{l}\text { Section I: } \\
\text { Structural frame }\end{array}$ & $1,5,9,13,17,21,25,29$ & $8-40$ & $($ mean $\geq 4.0)$ \\
Human resource frame & $2,6,10,14,18,22,26,30$ & $8-40$ & $($ mean $\geq 4.0)$ \\
Political frame & $3,7,11,15,19,23,27,31$ & $8-40$ & $($ mean $\geq 4.0)$ \\
Symbolic frame & $4,8,12,16,20,24,28,32$ & $8-40$ & $($ mean $\geq 4.0)$ \\
Section II: & $1 \mathrm{a}, 2 \mathrm{a}, 3 \mathrm{a}, 4 \mathrm{a}, 5 \mathrm{a}, 6 \mathrm{a}$ & $6-24$ & $($ mean $\geq 3.2)$ \\
Structural frame & $1 \mathrm{~b}, 2 \mathrm{~b}, 3 \mathrm{~b}, 4 \mathrm{~b}, 5 \mathrm{~b}, 6 \mathrm{~b}$ & $6-24$ & $($ mean $\geq 3.2)$ \\
Human resource frame & $1 \mathrm{c}, 2 \mathrm{c}, 3 \mathrm{c}, 4 \mathrm{c}, 5 \mathrm{c}, 6 \mathrm{c}$ & $6-24$ & $($ mean $\geq 3.2)$ \\
Political frame & $1 \mathrm{~d}, 2 \mathrm{~d}, 3 \mathrm{~d}, 4 \mathrm{~d}, 5 \mathrm{~d}, 6 \mathrm{~d}$ & $6-24$ & $($ mean $\geq 3.2)$ \\
Symbolic frame & & & \\
\hline
\end{tabular}




\section{Table 4}

Leadership Frames and Descriptors

\begin{tabular}{|c|c|}
\hline Leadership Frame & Descriptors \\
\hline Structural & 1. Efficiency and organization \\
\hline \multirow[t]{4}{*}{ Leader in a directive role } & 2. Clear, well-developed control systems and policies \\
\hline & 3. Managing systems, structures \\
\hline & 4. Budgeting \\
\hline & 5. Planning, goal setting and accomplishment \\
\hline Human Resource & 1. Evaluation, reports, records \\
\hline \multirow[t]{6}{*}{ Leader in a facilitative role } & 2. Developing a motivated staff, empowerment efforts \\
\hline & 3. Involving staff - task forces, teams, committees \\
\hline & 4. Assisting and advocating for others \\
\hline & 5. Recognizing and rewarding achievement \\
\hline & 6. Communicating \\
\hline & 7. Training, recruiting \\
\hline Political & 1. Managing conflict among different groups \\
\hline Leader in a collaboration & 2. Building organizational alliances, networking \\
\hline \multirow[t]{2}{*}{ building role } & 3. Obtaining needed resources through negotiation, bargaining \\
\hline & 4. Communicating the organizational image externally \\
\hline Symbolic & 1. Communicating the organizational image internally \\
\hline \multirow[t]{3}{*}{ Leader in a visionary role } & 2. Building a vision and commitment to the vision \\
\hline & 3. Creating or revitalizing ceremonies, culture and symbols \\
\hline & 4. Using personal effort to set example of "best practices" \\
\hline
\end{tabular}

4. Using personal effort to set example of "best practices"

Note. Adapted from Bolman \& Deal (1992), Bensimon \& Neumann (1990), and Bensimon, Neumann, \& Birnbaum (1989). 


\section{Summary}

This chapter describes the research method and rationale for this study of leadership orientations of a sample of WVUES leaders and a representative group of county constituents. The procedures were designed to obtain the most accurate and rich data without overburdening the study participants. Statistical tests at the .05 alpha level were used. 


\section{Chapter 4}

Results

This chapter presents the major findings of the study regarding the leadership styles of West Virginia University Extension Service (WVUES) County Program Coordinators as measured by the Leadership Orientations (Self) Survey and the Leadership Orientations (Other) Survey by Bolman and Deal (Bolman, 2001). The findings are organized according to each research question. The Statistical Product and Service Solutions (SPSS) software was used for descriptive and statistical procedures. An alpha of .05 was used to establish significance level.

\section{Survey Responses}

There were two populations involved in this study: County Program Coordinators employed by the WVUES and County Extension Service Committee members. At the time of the study, there were 53 County Program Coordinators and 35 were invited to participate in the study. The 18 coordinators who were not invited to participate were not selected based on two possible reasons. First, coordinators with less than one year of experience in this leadership role were not selected to participate. There were 12 counties with a coordinator with less than one year of experience. Second, those who had an employee-supervisory relationship with the author were not selected. Six County Program Coordinators were currently supervised by the researcher. Of the 35 coordinators who met the qualifications to be in the study, 33 responded and participated. The study sample was $62 \%$ of the population and $94 \%$ of those eligible to participate.

The second population included current members of the WVUES County Extension Service Committees. There were approximately 400 committee members statewide. To be invited to participate in this study, two criteria had to be met. First, members had to serve in one of the 35 counties eligible to be in the study. There were 260 committee members who represented the 35 
counties in the County Program Coordinator sample in the study. Committee members had to have at least one year of committee experience to participate. A total of 240 committee members met these two eligibility criteria and were invited to participate. They were informed about the study by the Director of the West Virginia University Extension Service via a mailed communication. Follow-up cover letters and surveys were sent to members. Of those 240 invited members, 180 agreed to participate by completing a survey of the County Program Coordinator in their county. The 180 respondents was a response rate of $75 \%$. From these 180 surveys, 13 were eliminated because the coordinator in their county $(n=2)$ did not participate. This resulted in 167 committee member surveys. There were 15 surveys eliminated from the data set due to missing values. This resulted in a final total of 152 completed Leadership Orientation (Other) Surveys from committee members. This was $63 \%$ of the population sample. Survey response data are featured in Table 5. 
Table 5

Population, Sample, and Survey Responses

\begin{tabular}{lccc}
\hline \multicolumn{1}{c}{ Population } & No. invited to & No. completed & Percent of \\
& participate & surveys & population \\
\hline County Program & 35 & 33 & 62 \\
Coordinators & & & \\
$(n=53)$ & & & \\
\hline Extension Service & 240 & & \\
Committee & & & \\
members & & \\
$(n=400)$ & & & \\
\end{tabular}

Note. Each of the 152 committee members completed surveys, rating the coordinator in their county. An average of 4.6 committee members rated each coordinator.

\section{County Program Coordinator Data}

County Program Coordinator demographic data are presented in Table 6. Of the 33 respondents, $72.7 \%$ were male $(n=24)$ and $27.3 \%$ were female $(n=9)$. There were $30.3 \%$ with less than 10 years of extension experience $(n=10), 36.4 \%$ with 10 to 20 years experience $(n=12)$, and $33.3 \%$ with more than 20 years experience $(n=11)$. There was a range of one to 33 years experience and an average of 16 years. By program center assignment, $69.7 \%$ were in the Program Center for Agriculture, Natural Resources, and Community Development $(n=23)$ and $30.3 \%$ were in the Program Center for $4-\mathrm{H}$ and Youth, Family, and Adult Development $(n=10)$. Coordinators were also categorized by the number of professional office staff in their county. 
There were $33.3 \%$ with one staff in their county $(n=11) ; 36.4 \%$ with two $(n=12)$; and $30.3 \%$ with three $(n=10)$.

Table 6

Demographic Variables of County Program Coordinators $(n=33)$

Frequency Percent

Gender

Male

24

72.7

Female

9

27.3

Years of extension experience

$<10$ years

10

30.3

10-20 years

12

36.4

$>20$ years

11

33.3

Program center assignment ${ }^{\mathrm{a}}$

ANRCD

4-HYFAD

Number of office staff

1 office staff

2 office staff

3 office staff
23

10

69.7

30.3

11

33.3

12

36.4

10
30.3

Note. ${ }^{\text {a }}$ County Program Coordinators were assigned to one of two program centers Agriculture, Natural Resources, and Community Development (ANRCD) or 4-H and Youth, Family, and Adult Development (4-HYFAD). 


\section{Dealing with Missing Values}

All Leadership Orientations (Self) Surveys received from County Program Coordinators were complete. However, the 180 surveys returned from committee members had some missing values. The 32-item survey Section I contained eight questions on each leadership frame. If a survey response for Section I had two or more missing values for one or more of the leadership frames, the survey was not included in the study. The rationale was if a survey had two or more missing values, this $25 \%$ of missing data would jeopardize the validity and accuracy of the leadership frame score. There was a total of 166 missing values in Section I of all the surveys, or an average of 5 blanks per survey. A total of 15 surveys were eliminated from the study because of missing values for two or more questions on any one leadership frame.

Among the Section I questions most frequently left unanswered, the political frame questions tended to be the ones most frequently omitted. Nearly $37 \%$ of the missing values were for questions on the political frame. The portion of missing values for the structural frame questions was $27 \%$; for the human resource frame questions was $16 \%$; for the political frame questions was $37 \%$; and for the symbolic frame questions was $20 \%$.

Based on further evaluation of the data, Section II of the survey posed the greatest problem due to missing values. Questions in Section II required a forced-choice response. Each Section II question forced the respondent to rank order the County Program Coordinator's leadership skills. Some committee members left blanks and some filled in their responses incorrectly. Committee members may not have understood the directions or chose not to follow the directions. Because of the prevalence of missing values in Section II, the data from this section were not included in the study. Section II of the Bolman and Deal survey instruments is not always used. In fact, 
many recent studies only include Section I (Chang, 2004; Hollingsworth, 1995; Mosser, 2000;

Small, 2002).

\section{Reliability of Scales}

Bolman and Deal's Leadership Orientations (Self) Survey and Leadership Orientations (Other) Survey have been used in many different settings including business, industry, and higher education. They have been used with many countries and cultures. Only one study is known to have used the Leadership Orientations (Self) Survey to examine extension leaders (Hollingsworth, 1995). No studies have used both the "self" and "other" versions of the instrument to research extension leaders. Considering that the instruments have not been tested with the populations included in this study, the internal consistency was tested. Each of the 32 items on the surveys were checked by computing Cronbach's alpha coefficients. The 32 items were categorized according to which leadership frame was measured. On the Leadership Orientations (Self) Survey, coordinators rated the extent to which each statement was true of them. On the Leadership Orientations (Other) Survey, committee members rated the extent to which each statement was true of the coordinator in their county. Respondents used a five-point Likert scale ( 1 =Never, $2=$ Occasionally, $3=$ Sometimes, 4=Often, and 5=Always).

Chronbach's alpha on each of the four leadership frames was calculated for both the County Program Coordinator $(n=33)$ and County Extension Service Committee member responses $(n=152)$. Regarding the coordinator alpha, the coefficient alpha on the 32 survey items ranged from 0.9141 to 0.9211 . A total alpha was 0.9236 . Coefficient alpha for the committee member responses ranged from 0.9768 to 0.9780 . The total alpha for this group of survey responses was 0.9786. This compares with Bolman and Deal's reliability analysis of 0.920 . Reliability analysis 
data are presented in Table 7, comparing alphas of coordinator responses, committee member responses, and Bolman and Deal's responses.

Table 7

Comparison of Reliability Analyses

\begin{tabular}{lcccc}
\hline \multicolumn{1}{c}{ Leadership } & No. of & County Program & Extension Service & Bolman and Deal's \\
Frame & Survey & Coordinator & Committee & Alpha \\
& Items & Alpha & Alpha & $(n=1,309)$ \\
& & $(n=33)$ & $(n=152)$ & \\
\hline Structural & 8 & 0.8412 & 0.9251 & 0.920 \\
Human resource & 8 & 0.7500 & 0.9503 & 0.931 \\
Political & 8 & 0.7574 & 0.9175 & 0.913 \\
Symbolic & 8 & 0.8453 & 0.9288 & 0.931 \\
Total & 32 & 0.9236 & 0.9786 & 0.920 \\
\hline
\end{tabular}

Note. Bolman and Deal data were computed from 1,309 peer responses on the Leadership

Orientations (Other) Survey and were from Lee Bolman's home page at http://www.bloch.umkc.edu/classes/bolman/new page 1.htm.

\section{Major Findings}

\section{Research Question 1}

Which leadership styles - no frame style, single frame style, paired frame style or multiple frame style - do West Virginia County Program Coordinators perceive themselves to use, as measured by the Leadership Orientations (Self) Survey? 
Survey data from 33 County Program Coordinators were aggregated in several ways. First, total scores for each leadership frame were calculated for each coordinator. Following the initial score analysis for each frame, leadership frame choice was determined. A coordinator with a mean score of 4.0 or higher in a leadership frame was categorized as making that leadership frame choice. Next, the frame choices were analyzed. Coordinator scores revealed the actual use of nine different patterns out of sixteen possible patterns or combinations of frames. These nine patterns were subsequently categorized into four basic leadership styles: no frame style, single frame style, paired frame style, and multiple frame style. The most predominant leadership style was no frame style, which was endorsed by almost two-fifths of the coordinators. The single frame style was the second most predominant, and was endorsed by about one-third of the coordinators. Among the respondents reportedly using a single frame style, nearly half used the structural frame, and nearly half used the human resource frame. The paired frame style occurred in $15 \%$ of coordinators. Even fewer, $12 \%$, perceived that they used multiple frames. The frequency distributions of leadership frame scores, frame choice patterns, and leadership frame style of coordinators are presented in Table 8. 
Table 8

Frequency Distribution of County Program Coordinator (CPC) Leadership Style (n=33)

\begin{tabular}{lccc}
\hline Leadership style & $\begin{array}{c}\text { Frequency } \\
\text { score } \geq 4.0\end{array}$ & $\begin{array}{c}\text { Percent } \\
\text { score } \geq 4.0\end{array}$ \\
\hline No frame style & & 13 & 39.4
\end{tabular}

Single frame style

1. Structural 5

2. Human resource

5

15.2

3. Political

4. Symbolic

1

3.0

Total single frame style

11

33.4

Paired frame style

1. Structural-human resource

4

2. Structural-political

3. Structural-symbolic

4. Human resource-political

5. Human resource-symbolic

6. Political-symbolic

1

3.0

Total paired frame style

5

Multiple frame style

1. Structural-human resource-political

2. Structural-human resource-symbolic

13.0

13.0

3. Structural-political-symbolic

4. Human resource-political-symbolic

5. Structural-human resource-political-symbolic

2

6.1

Total multiple frame style

4

12.1 
Scores for each of the leadership frames further illustrate the leadership style. The human resource frame had the highest rate of endorsement. The human resource mean score for all County Program Coordinators was $3.9(S D=.457)$; the structural frame mean score was 3.7 $(S D=.568)$; the political frame mean score was $3.5(S D=.484)$; and the symbolic frame mean score was $3.3(S D=.599)$. Coordinators rated their use of the human resource frame higher than the other frames. In contrast, they perceived that they used the symbolic frame less often than any other frame. The mean score for each leadership frame was below 4.0, which was the defined score for frequent frame use. These data are presented in Table 9.

Leadership frame scores influence leadership frame patterns and styles. Among those who reported a single frame style, half used the structural frame frequently and half used the human resource frame frequently. The most common paired frame style was the structural and human resource approach. Those who rated 4.0 or higher for three or four frames had a pattern of structural-human resource-political, or a pattern of structural-human resource-symbolic. Because the human resource frame had the highest scores, it was often used as a single pattern, paired with the structural frame, and in multiple frame combinations as well. However, no conclusions may be drawn because of the small number of multiple frame style coordinators. 
Table 9

Mean Score, Mean Score Range, and Standard Deviation

of County Program Coordinators' Self-Rated Leadership Frames ( $n=33$ )

\begin{tabular}{lccc}
\hline Leadership frame & Mean score & Mean score range & Standard deviation \\
\hline Structural & 3.7 & $3-5$ & .568 \\
Human resource & 3.9 & $3-5$ & .457 \\
Political & 3.5 & $2-4$ & .484 \\
Symbolic & 3.3 & $2-5$ & .599 \\
\hline
\end{tabular}

To summarize Research Question 1, coordinators most often perceived themselves to use no one particular leadership style. One-third of the respondents reported they used a single frame style. The next most frequently used style was the paired frame style followed by the multiple frame style. Consequently, the most frequently used style was the no frame style and the least used was the multiple frame style. Furthermore, within each of the leadership styles, certain frames appeared more frequently than others. Of those who reported a single frame style, the respondents were divided equally between the human resource and structural frames. Human resource was the predominant frame followed by the structural, political, and symbolic frame.

\section{Research Question 2}

Are there statistically significant relationships between West Virginia University Extension Service County Program Coordinator leadership styles as measured by the Leadership 
Orientations (Self) Survey and selected background characteristics of gender, years of extension experience, program center assignment, and number of office staff?

The leadership styles and coordinator characteristics were examined through descriptive statistics and statistical analysis. The relationships between leadership styles and selected characteristics were determined by computing Pearson correlation coefficients. Correlations for leadership styles - no frame style, single frame style, paired frame style and multiple frame style - were calculated with each independent variable. The independent variables were gender, years of extension experience, program center assignment, and number of office staff. Coding for the gender variable was $1=$ male and $2=$ female. Coding for years of extension experience was $1=$ less than 10 years, $2=10$ to 20 years, and $3=$ more than 20 years. Table 10 presents frequency distributions by leadership style and background characteristics as well as correlations.

Regarding gender, male respondents reported using the no frame style more frequently, followed by single frame style the next most frequently, and the paired frame style, then multiple frame style. This is similar to the styles displayed for the entire group. Females appeared to have somewhat similar patterns although the trend was not as pronounced. The very low number of cases in those cells makes it difficult to make interpretations from the data. The relationship between gender and leadership style was not significantly correlated.

The percentage distribution of leadership styles appeared to be spread out evenly among all categories of years of extension experience and styles. There was a larger percentage of no frame style use among the 10 to 20 year group than in other groups. The relationship between years of extension experience and leadership style was not significantly correlated.

Leadership styles and coordinator program center assignment data were also analyzed. Again, the low $n$ must be acknowledged. However, coordinators assigned to the Program Center 
for Agriculture, Natural Resources, and Community Development reported the use of the no frame and single frame styles the most. An equal number of coordinators reported the no frame style and the single frame style. Fewer reported frequent use of paired frame and multiple frame styles. In contrast, all coordinators assigned to the Program Center for 4-H and Youth, Family, and Adult Development reported the frequent use of the no frame style or single frame style. None of these coordinators rated themselves as frequently using paired frame or multiple frame styles. A Pearson correlation coefficient of -.404 indicated a significant negative correlation $(p<.05)$ between program center assignment and the leadership style. The Agriculture, Natural Resources, and Community Development coordinators exhibited the paired and multiple frame styles more frequently than did the other group of coordinators assigned to the Program Center for 4-H and Youth, Family, and Adult Development. This difference was found to be significant. Lastly, the data relevant to leadership styles and number of professional office staff were explored. Coordinators were categorized as having one, two, or three office staff in their county. Leadership styles appeared to be fairly evenly distributed across the categories of number of office staff. According to the Pearson correlation coefficients, no statistically significant relationship existed between leadership styles and the number of office staff. 
Table 10

Correlations and Frequency Distributions by Leadership Styles and Characteristics

\begin{tabular}{|c|c|c|c|c|c|c|c|c|}
\hline $\begin{array}{c}\text { Pearson } \\
\text { correlation } \\
r \\
\end{array}$ & \multicolumn{2}{|c|}{$\begin{array}{c}\text { No frame } \\
\text { style } \\
\end{array}$} & \multicolumn{2}{|c|}{$\begin{array}{c}\text { Single } \\
\text { frame style }\end{array}$} & \multicolumn{2}{|c|}{$\begin{array}{c}\text { Paired } \\
\text { frame style }\end{array}$} & \multicolumn{2}{|c|}{$\begin{array}{r}\text { Multiple } \\
\text { frame style }\end{array}$} \\
\hline & $\mathrm{F}$ & $\%$ & $\mathrm{~F}$ & $\%$ & $\mathrm{~F}$ & $\%$ & $\mathrm{~F}$ & $\%$ \\
\hline
\end{tabular}

Gender

Male $(n=24)$

$r=.114 \quad 10 \quad 30.3 \quad 8$

24.24

12.12

6.1

Female $(n=9)$

$$
p=.527
$$

9.13

9.1

$\begin{array}{lll}1 & 3.0 & 2\end{array}$

6.1

Years of experience

$\begin{array}{llllllllll}<10 \text { yrs. }(n=10) & r=.036 & 3 & 9.1 & 3 & 9.1 & 3 & 9.1 & 1 & 3.0 \\ 10-20 \text { yrs. }(n=12) & p=.843 & 7 & 21.2 & 3 & 9.1 & 1 & 3.0 & 1 & 3.0 \\ >20 \text { yrs. }(n=11) & & 3 & 9.1 & 4 & 12.1 & 2 & 6.1 & 2 & 6.1\end{array}$

Program center ${ }^{\mathrm{a}}$

$\begin{array}{llllllllll}\operatorname{ANRCD}(n=23) & r=-.404^{*} & 7 & 21.2 & 7 & 21.2 & 5 & 15.2 & 4 & 12.1 \\ \text { 4-HYFAD }(n=10) & p=.020 & 6 & 18.2 & 4 & 12.1 & - & - & - & -\end{array}$

Number of office staff

$\begin{array}{llllllllll}1 \operatorname{staff}(n=11) & r=.001 & 4 & 12.1 & 4 & 12.1 & 1 & 3.0 & 2 & 6.1 \\ 2 \operatorname{staff}(n=12) & p=.995 & 5 & 15.2 & 5 & 15.2 & 1 & 3.0 & 1 & 3.0 \\ 3 \operatorname{staff}(n=10) & & 4 & 12.1 & 2 & 6.1 & 3 & 9.1 & 1 & 3.0\end{array}$

Note. ${ }^{a}$ County Program Coordinators were assigned to one of two program centers: $\overline{\text { (1) }}$

Agriculture, Natural Resources, and Community Development (ANRCD) or (2) 4-H and Youth, Family, and Adult Development (4-HYFAD).

$* p>.05$ 
To summarize Research Question 2, there was a statistically significant negative correlation, $p>.05$, between program center assignment and leadership style. In comparing County Program Coordinators assigned to the Program Center for Agriculture, Natural Resources, and Community Development with those who were assigned to the Program Center for 4- $\mathrm{H}$ and Youth, Family, and Adult Development, the former were significantly more likely to report frequent use of the paired and multiple frame leadership styles. In contrast, the correlations of leadership style with (a) gender, (b) years of experience, and (c) number of office staff were not significant, $p>.05$.

\section{Research Question 3}

Which leadership styles - no frame style, single frame style, paired frame style or multiple frame style - do County Extension Service Committee members perceive the County Program Coordinator in their county to use, as measured by the Leadership Orientations (Other) Survey? How do these results, based on County Extension Service Committee member (other) perceptions, compare with the results of County Program Coordinator (self) perceptions (Research Question 1)?

Research Question 3 describes the leadership styles of County Program Coordinators from the perspective of their County Extension Service Committee members. Leadership Orientation (Other) Surveys were completed by 152 committee members. A range of two to eight committee members completed the survey rating for each coordinator. The average number of committee members rating their coordinator was 4.6. Committee member mean scores were computed by aggregating the committee member scores which corresponded to each individual coordinator. This resulted in one committee member mean score for each leadership frame for each coordinator. The two scores, County Program Coordinator (self) and County Extension Service 
Committee member (other), were compared. A mean score of 4.0 or higher in a leadership frame was categorized into the four basic leadership styles: no frame style, single frame style, paired frame style, and multiple frame style.

Leadership styles were compared according to coordinator self-ratings and committee member mean ratings. These data are presented in Table 11. The majority of committee member mean scores, $54.5 \%$, indicated a multiple frame style. Committee member mean scores for multiple frame style use contrasts sharply with that of the coordinator styles. Only $12.1 \%$ of coordinators reported frequent use of the multiple frame style.

Leadership frame scores by committee members were consistently higher than self-rated coordinator scores. Table 12 displays the descriptive data and compares scores of 4.0 or higher for each frame. Based on the mean scores, committee members perceived coordinators to use the structural, human resource, political, and symbolic frames frequently. The highest percent scores were the structural and human resource frames, both with $66.7 \%$ of the committee member mean scores. The next highest percentage score was the political frame, with $54.5 \%$. Also, $51.5 \%$ of committee members rated their coordinator as frequently using the symbolic frame style. In contrast to committee member ratings, the percentage of coordinators whose mean score was 4.0 or higher were $39.3 \%$ structural, $39.3 \%$ human resource, $12.1 \%$ political, and $15.1 \%$ for the symbolic frame. Committee member mean scores were much higher than coordinator scores on all four leadership frames. 
Table 11

Frequency Distribution of Leadership Styles as Rated by County Program Coordinators (CPC) and County Extension Service Committee Members

Leadership style

$\underline{\text { Frequency score } \geq 4.0 \quad \underline{\text { Percent }} \text { score } \geq 4.0}$

CPC Committee CPC Committee

$(n=33) \quad$ member $\quad(n=33) \quad$ member

Mean Mean

$(n=152) \quad(n=152)$

No frame style

13

7

39.4

21.2

Single frame style

1. Structural

2. Human resource

3. Political

4. Symbolic

Total single frame style

Paired frame style

5. Structural-human resource

6. Structural-political

7. Structural-symbolic

8. Human resource-political

9. Human resource-symbolic

10. Political-symbolic

Total paired frame style
5

5

$-$

1

11

1

15.2

6.0

9.0

3.0

3.0

33.4

18.2
4

$-$

1

$12.1 \quad 3.0$

$-\quad 3.0$
$-\quad 30$

$-$

$-$

1

5

1

$-$

$-$

$-$

3.0

15.1

6.0 
Leadership style

$\underline{\text { Frequency score } \geq 4.0 \quad \text { Percent } \text { score } \geq 4.0}$

CPC Committee CPC Committee

$(n=33) \quad$ member $\quad(n=33) \quad$ member

Mean Mean

$(n=152) \quad(n=152)$

\begin{tabular}{|c|c|c|c|c|c|}
\hline \multicolumn{6}{|c|}{ Multiple frame style } \\
\hline 11. & Structural-human resource-political & 1 & 1 & 3.0 & 3.0 \\
\hline 12. & Structural-human resource-symbolic & 1 & 2 & 3.0 & 6.0 \\
\hline 13. & Structural-political-symbolic & - & - & - & - \\
\hline 14. & Human resource-political-symbolic & - & - & - & - \\
\hline 15. & Structural-human resource-political- & 2 & 15 & 6.1 & 45.5 \\
\hline & symbolic & & & & \\
\hline \multicolumn{2}{|c|}{ Total multiple frame style } & 4 & 18 & 12.1 & 54.5 \\
\hline
\end{tabular}

Note. There were 33 coordinators who rated themselves at or above 4.0 on $0,1,2,3$, or 4 of the four leadership frames. The committee member mean was calculated for each of the 33 coordinators based on 152 surveys, an average of 4.6 per coordinator. 
Table 12

Frequency Distributions of Leadership Frame Scores as Rated by County Program Coordinators (CPC) and County Extension Service Committee Members

\begin{tabular}{lcccc}
\hline & \multicolumn{2}{c}{ Frequency score $\geq 4.0$} & \multicolumn{2}{c}{ Percent score $\geq 4.0$} \\
\multicolumn{1}{c}{ Leadership frame } & CPC & Committee & CPC & Committee \\
& $(n=33)$ & member & $(n=33)$ & member \\
& & Mean & & $(n=152 / 33)$ \\
& 13 & 22 & 39.3 & 66.7 \\
Structural & 13 & 22 & 39.3 & 66.7 \\
Human resource & 4 & 18 & 12.1 & 54.5 \\
Political & 5 & 17 & 15.1 & 51.5 \\
Symbolic & & & & \\
\hline
\end{tabular}

Note. There were 33 coordinators who rated themselves on each of the four leadership frames. The committee member mean was calculated for each of the 33 coordinators based on 152 surveys. A score of 4.0 or greater for a leadership frame is defined as a leadership frame choice.

In summary, County Program Coordinators perceived themselves to use fewer frames than did committee members who reported their views about the coordinators. The leadership style of no frame style was reported the most frequently among coordinators, followed by single frame style, paired frame style, and multiple frame style. Obviously, committee members perceived their coordinators much differently. The majority of committee members rated coordinators as using all four frames frequently. Although the survey results of coordinators and their committee 
members show very different trends with leadership styles, there was a consistent trend in leadership frame choice. Both coordinators and committee members perceived the human resource frame as used most frequently, followed by the structural frame, political frame, and symbolic frame as used least often. While they generally agreed on which frames were used most and least often, the differences were in the extent to which the frames were used.

\section{Research Question 4}

Are there statistically significant relationships between County Program Coordinator leadership styles as identified by the County Extension Service Committee members, and County Program Coordinator leadership styles as self-identified by the coordinators?

To determine whether or not a relationship existed between leadership styles identified by coordinators and committee members, Pearson's correlation coefficients were computed. No significant relationships existed between the leadership styles based on committee member ratings and the self-identified leadership styles of coordinators $(r=.205)$. However, a significant relationship was found when the analyses were computed with subgroups. There was a significant positive relationship between coordinators with self-rated multiple frame styles and committee member mean ratings of multiple frame styles $(r=.361)$. When compared to coordinators with no frame, single frame, or paired frame styles, coordinators with a selfidentified multiple frame style were more likely to also be viewed as multiple frame style leaders by their committee members.

To further explore the two perspectives, correlations with coordinator and committee member mean frame scores were computed as Pearson's correlation coefficients. Table 13 displays these data. There were no significant relationships between the two sets of scores for any of the four leadership frames. Also, the human resource frame does show a higher degree of 
correlation and significance than the other frames, due to the frequent choice of that frame.

Frame choice was defined as a score of $\geq 4.0$ on the survey.

In addition to the correlation procedure, the descriptive data were reviewed in terms of the frequency of agreement between coordinators and committee members. Eight out of 33 matched coordinators and committee member mean ratings agreed on leadership style. Twenty-four percent of coordinators' self-identified leadership styles exactly matched that of the committee members' mean ratings. Of these eight agreements, two agreed on a no frame style, two agreed on a single frame style, none agreed on a paired frame style, and four agreed on a multiple frame style. 
Table 13

Correlations of County Program Coordinator (CPC) Ratings with County Extension Service Committee (ESC) Members' Mean Ratings

CPC-ESC matched leadership style

\section{Pearson Correlation $r \quad p$}

No frame style

0.038

.835

Single frame style

0.270

.128

Paired frame style

0.023

.898

Multiple frame style

$0.361 *$

.039

CPC-ESC matched leadership frame scores

Structural

0.122

.499

Human resource

0.136

Political

0.075

.678

Symbolic

0.097

Note. $p=<.05$

\section{Research Question 5}

What are the critical leadership incidents as described by County Program Coordinators, as measured by the Leadership Orientations (Self) Survey? How do these descriptions compare to the leadership styles?

In contrast to Research Questions 1-4, Research Question 5 was a qualitative approach to understanding leadership orientations from the perspectives of County Program Coordinators. This qualitative inquiry was designed to explore leadership beyond what could be quantified or 
discovered through the Bolman and Deal survey. Four questions were added to the Leadership Orientations (Self) Survey to elicit descriptive information about the critical leadership incidents of coordinators. The questions were:

1. What do you consider the most significant leadership accomplishment as a County Program Coordinator?

2. Could you describe the specific leadership skills or behaviors you used to accomplish this?

3. As a County Program Coordinator, what was the greatest challenge you have encountered?

4. Could you please describe the specific leadership skills or behaviors you used in addressing this challenge?

The responses for these open-ended questions were analyzed by the researcher and two field experts. The field experts were selected based on their extensive knowledge and experience in both qualitative research methods and the extension organization. The use of several different researchers, or investigator triangulation, helped ensure appropriate objectivity (Patton, 1990). The researchers used the descriptors listed in Table 4 to conduct the content analysis. Each response was categorized into one or more leadership frames, according to the frame descriptors. The three analyses from the researcher and the two field experts were compared. Responses for which there was agreement were organized into a content matrix. The matrix summarized coordinator responses to the four questions as well as the leadership styles identified in the previous survey sections, Leadership Orientations (Self) Survey, Section I. The content matrix was analyzed for similarities and differences between the self-identified leadership styles, 
leadership styles identified by committee members, and leadership styles from the open-ended question responses.

From the content analysis, certain themes emerged including overall and question-specific concepts. The responses to all four questions mirrored the leadership frame scores, which were identified in the other parts of the survey. Responses categorized as human resource frames were predominant. Structural frame responses were also frequent. Similar to the survey scores, responses to these questions were much less likely to fall into the political and symbolic frames than the structural and human resource frames. One exception was the responses to the first question. Half the responses related to the political frame. The other three questions followed the frame pattern of human resource, structural, political and symbolic.

Another overarching impression was that responses were often expressed in a way that conveyed the complexity and multidimensional nature of leadership. For example, one coordinator referred to "my abilities as a team player to keep funding at a level to meet the challenges of a growing county extension program." This response described the context of a coordinator's assignment. It also appeared to demonstrate an understanding that teamwork (human resource frame) and continued funding (structural frame) may determine future success in accomplishing a goal of program growth (structural frame).

In response to question one, the majority of coordinators cited securing funding and meeting budget expectations as their most significant accomplishment. This response was categorized as use of structural leadership frame skills. Responses also had elements of the political and human resource frames. For example, one coordinator's major accomplishment was “my relationship with the County Commission as a person they can count on for answers." Another said, "I think my most significant accomplishment is that the staff works together as a team. As a result of this 
we set goals and accomplish them. Although we have had tough times, we have made it through and have a strong staff." Coordinators have responsibilities for both internal relationships with office staff and external relationships with funding bodies and constituent groups. This complexity underscores the need for leaders to employ a diverse, multiple frame skill set.

The second question asked County Program Coordinators to describe the specific leadership skills they used to accomplish the critical leadership incident they cited in the first question. Responses were very comprehensive and listed more than forty distinct leadership characteristics. Relationship building was a key element. Skills and behaviors used to build relationships primarily included the human resource frame. However, interpersonal skills and behaviors involving the three other frames were also used. A few responses were more like personal traits rather than leadership traits. Examples of these "difficult to categorize" skills included tenacity, risk taking, professionalism, and challenging the process.

In question three, coordinators were asked to describe their greatest challenge. The majority of responses related to situations about authority and relationships. Frustration with co-workers was clearly expressed, as in one candid comment that was reiterated by several others, "Having to be responsible for the actions of others while not having any supervisory rights." Second, budgets challenged coordinators. "Mandates from Morgantown for more money," exclaimed one respondent. A few listed political situations, such as community volunteer conflicts and competing for resources with other equally important county services. This question seemed to bring out more negative remarks than did the other questions. In addition to revealing the greatest personal leadership challenges, responses to this question provide a window into organizational challenges facing the West Virginia University Extension Service. Comments such as "receiving little notice of appointment and no training," "lack of support from 
administration," and "deciding what requests/requirements from Morgantown were important enough to follow through with and what were wastes of time" demonstrate issues that some coordinators feel need to be resolved. Furthermore, some of these comments convey a feeling that their coordinator efforts are not as well understood nor appreciated by central administration as the coordinators would like.

Lastly, when asked what skills they used to address this challenge, County Program Coordinators most often cited leadership skills which were categorized by the researchers as human resource skills. Responses ranged from a simple, one word answer, "patience," to lengthy paragraphs on a personnel issue. One coordinator described a successful strategy related to human resource and political frame skills: "I have developed a good relationship with the person in charge of the budgets at the BOE [Board of Education]. Because of this, I am able to get reports and his help fairly quickly. This person is highly stressed. So I found out what he likes to do on his off time and talk with him about the projects he is working on. As we talk, he prints the reports I need, makes corrections, and helps me understand the budget. I can usually get a budget report in an hour or less instead of a week to a week and a half." Some coordinators related to structural frame skills such as "established a monthly schedule board," "time management,...to do lists and being task oriented are my best weapons of defense." They also used symbolic frame skills, as expressed in "I set the example by cooperating first" and "I remind them of our mission." One coordinator commented "I split firewood" to cope with the challenge. This was indicative of the openness and honesty of the respondents.

To summarize Research Question 5, the critical leadership incidents described by County Program Coordinators reflected all four leadership frames. Responses indicated that the four frames were used in a very similar pattern as identified by both coordinators and committee 
members using the Leadership Orientations Survey (Self) and Leadership Orientations Survey

(Other). Content analysis of all the responses revealed that the human resource frame was used most often, followed by the structural frame, the political frame, and the symbolic frame.

Examples of coordinators' greatest accomplishments, challenges, and skills, appeared to confirm the leadership frame styles of survey scores. However, it was not possible to discern any similarities or differences in leadership frame style use by responses to the open-ended questions. After analysis of the responses, coordinators who were previously identified as using no frame, single frame, paired frame, or multiple frame patterns could not easily be categorized in the same way. However, the most notable finding from this part of the survey was the set of responses alone. Expressions about leadership accomplishments and challenges exposed the personal side of the leadership experience. Coordinators gave insight into the complexity of their individual roles and the overall organization.

\section{Summary}

This study explored the leadership frame styles of West Virginia University Extension Service County Program Coordinators. Participants in the study included 33 full-time university faculty members located in county extension offices throughout the state. They were designated as County Program Coordinators and, in this capacity, interacted with the County Extension Service Committees. Members of these committees $(n=152)$ also participated in this study.

Two survey instruments were used to collect data from the County Program Coordinators and County Extension Service Committee members. Bolman and Deal's Leadership Orientations (Self) Survey was completed by coordinators to rate their use of four leadership frames - structural, human resource, political, and symbolic. Frame scores were used to determine the leadership styles. The Leadership Orientation (Other) Survey was completed by 
committee members and rated their coordinator's use of the four leadership frames. Four questions were added by the researcher to the existing survey questions.

Five research questions guided the study. The Statistical Product and Service Solutions (SPSS) software was used for descriptive and statistical procedures. Descriptive procedures were used to investigate Research Question 1 and 3. Research Question 2 and 4 used Pearson's correlation coefficients. An alpha of .05 was used to establish significance level. Research Question 5 used descriptive data and qualitative content analysis procedures.

Research Question 1 examined which leadership frame style County Program Coordinators perceive themselves to use. The majority of coordinators reported they do not frequently use any of the leadership frames. The no frame style was the most predominant style. Some coordinators reported frequent use of a single frame style and very few reported frequent use of a multiple frame style.

The relationships between leadership frame styles and selected background characteristics were explored in Research Question 2. Findings showed a significant negative correlation $(p<.05)$ between program center assignment and the leadership frame style. Coordinators assigned to the Program Center for Agriculture, Natural Resources, and Community Development endorsed the paired and multiple frame styles more frequently than did coordinators assigned to the Program Center for 4-H and Youth, Family, and Adult Development. The correlations of leadership frame style with (a) gender, (b) years of experience, and (c) number of office staff were not significant $(p>.05)$.

Research Question 3 compared leadership frame style, as self-identified by County Program Coordinators and by committee members. Findings revealed that coordinators perceived themselves to use fewer frames than committee members perceived them to use. As described in 
Research Question 1, most coordinators were categorized as endorsing the no frame style followed by single frame style, paired frame style, and multiple frame style. Committee members perceived their coordinators differently. The majority of committee members rated coordinators as frequently using all four frames. A consistent trend in leadership frame choice emerged. Both the coordinators and committee members perceived the human resource frame as used most frequently followed by the structural frame, the political frame, and the symbolic frame. It appeared that one-fourth of the coordinators and committee members agreed on which frames were used most and least often despite clear differences in perceptions about the extent to which the frames were used.

Research Question 4 explored relationships between the two perspectives. Pearson's correlation coefficients were computed with coordinator and committee member mean frame scores. There were no significant relationships found between the coordinator scores and the committee member scores for any of the four leadership frames. Also, there were no significant relationships found between the leadership styles as assessed by the coordinators and the committee members. Upon further analysis of coordinators with each leadership style, a significant relationship was found with the multiple frame style coordinators. Committee members were likely to indicate their coordinators use a multiple frame style when the coordinators also rated themselves as multiple frame style. Coordinators with self-identified multiple frame styles were significantly more likely to also be viewed as multiple frame style leaders by their committee members, compared to coordinators with self-identified no frame, single frame, or paired frame styles.

Lastly, Research Question 5 investigated the critical leadership incidents described by County Program Coordinators and how they compared with leadership frame styles. A 
qualitative content analysis process was performed to answer this question. Coordinators were asked for written descriptions of significant accomplishments and challenges. They were also asked to describe the leadership skills they used. Descriptions were consistent with the leadership frame styles derived from survey scores. Human resource incidents and skills were frequently expressed. These related to internal human relations issues as well as external relationships with funding bodies and constituents. It appeared that the structural frame was the next most frequent frame followed by the political frame, and symbolic frame. Coordinator descriptions exemplified the complex and personal nature of leadership experiences.

In summation, the major findings of this study included a consistent pattern of leadership frame choice from the perceptions of County Program Coordinators and County Extension Service Committee members. In contrast, there were vastly different perceptions about the frequency of leadership frame use. Coordinators reported they used each leadership frame much less frequently than reported by the committee members. In comparing individual self-identified coordinator leadership frame styles with those identified by committee members, there were no significant relationships overall. However, when self-identified multiple frame coordinators were matched with committee members' leadership style ratings, a significant positive relationship was found. Lastly, there were no significant relationships between coordinator leadership frame styles and their background characteristics of gender, years of experience and office staffing levels. Program center assignment was the only characteristic found to have a significant relationship on leadership style. Those coordinators assigned to the Program Center for Agriculture, Natural Resources, and Community Development were significantly more likely to report frequent use of the paired and multiple frame styles than those from the Program Center for 4-H and Youth, Family, and Adult Development. 


\section{Chapter 5}

\section{Conclusions and Recommendations}

This chapter draws conclusions from the study's major findings and offers recommendations for future practice and research.

\section{Conclusions}

Conclusions based on the analyses of the five research questions which guided the study are explained in the following section.

\section{Leadership Styles of County Program Coordinators}

The majority of County Program Coordinators (39.4\%) reported none of the four leadership frames are used frequently. Therefore, the most predominant leadership style was the no frame style. The next most frequently used style was the single frame style (33.4\%), followed by the paired frame style (15.1\%), and multiple frame style (12.1\%). This study found that nearly threefourths of the coordinators had a no frame style or a single frame style. The central tenet of Bolman and Deal's leadership frame concept which was supported by their research was that "the ability to use multiple frames was a consistent correlate of effectiveness" (Bolman \& Deal, 1997, p. 278). Since the self-ratings of coordinators indicate very few use a multiple frame style, their effectiveness may be diminished in meeting the constant challenges facing leaders in their sphere of university public service.

The predominance of a self-rated no frame style is much higher in this study than was found in other recent studies of academic leaders. Studies do appear to vary widely in the percentage of leaders who use each style. In fact, most studies using the Leadership Orientations (Self) Survey found that the multiple frame style was used most frequently. Over two-thirds of area campus administrators rated themselves as frequently using a multiple frame style (Borden, 2000), 
campus security leaders rated themselves in a similar way (Wolf, 1998). Approximately onethird of student personnel professionals had a multiple frame style (McClellan-Holt, 2000). In another study, less than half of those leaders used multiple frame styles (Kelly, 1997). Compared to other studies, County Program Coordinators rated themselves much lower in each of the four frames which resulted in a no frame style. There are several potential reasons for this contrast in findings. The coordinator role is relatively new to the organization and it may lack role definition. There appears to be greater emphasis on managerial responsibilities rather than leadership. It is also possible that this finding is related to a lack of leadership training for coordinators.

Leadership styles are related to a variety of factors that affect the individual leader and the organization. The literature confirms that organizational climate (Mosser, 2000), organizational effectiveness (Bedore, 1998; Bethel, 1998), role conflict, job stress, satisfaction (Russell, 2000), and work ethic (Hollingsworth, 1995) have significant relationships with leadership style and frame use. For example, academic deans with a self-rated multiple frame style reported lower stress, higher satisfaction, and lower role-conflict compared to single frame style leaders (Russell, 2000). If coordinators in this study exhibited the patterns found in other studies, then the impact of their leadership styles may be far-reaching. It must be recognized that coordinators' leadership styles may have a profound effect on the WVUES in areas such as organizational effectiveness.

The coordinators in this study rated their use of each of the four leadership frames (structural, human resource, political, symbolic) as more than sometimes (a score of 3), but less than often (a score of 4). Reflecting on both the leadership styles and leadership frame scores, it was apparent that coordinators tended to use the human resource and structural frames the most, 
either separately or in combination. This pattern may be the result of coordinators' needs to deal with the most pressing tasks (e.g. budget and personnel) and to meet the expectations of their role. Conversely, the political and symbolic frames were used much less often and were seldom used in combination with the other frames. This was not surprising, given the type of peopleoriented work of the WVUES. Extension is a grassroots, community-based organization and its leaders must demonstrate human resource skills. They must also use structural skills, which best represents the university and federal extension system.

What appear to be lacking are political and symbolic frame skills. Considering today's competitive and unpredictable environment, political skills are extremely important. Symbolic skills help an organization discover a shared culture and spirit to create a future vision. Extension leaders need to be skilled in all four leadership frames. They need to be able to confidently and adeptly use each frame to assess any situation and make the best decisions. Again, Bolman and Deal claimed that, "Effectiveness as a manager was particularly associated with the structural frame, whereas the symbolic and political frames tended to be the primary determinants of effectiveness as a leader." (Bolman \& Deal, 1997, p. 278). If this is true, then extension leaders show more managerial skills than leadership skills. As noted previously, the coordinator role does emphasize more of a managerial role than that of a leadership role.

The self-reported frame scores and usage found in this study are generally supported in the literature. In the only available similar study of extension leaders, mean scores were 4.1 in human resource, 3.8 in structural, 3.6 in symbolic, and 3.3 in political (Hollingsworth, 1995). Other studies involving academic deans, department chairs, and leaders in similar positions show strong use of the human resource and structural frame use (Borden, 2000; Kelly, 1997; McClellan-Holt, 2000; Russell, 2000; Wolf, 1998). Bolman and Deal's research concurs with 
these results. It is concluded that self-reported frame scores are consistent with results found in the literature.

\section{Relationships Between Leadership Styles and Background Characteristics}

Research Question 2 explored the relationships between selected background characteristics of coordinators and leadership style. Results of the analyses showed no significant relationships between leadership style and gender, years of extension experience, and number of office staff. There was a significant difference between the leadership style and program center assignment. Coordinators in the Program Center for Agriculture, Natural Resources, and Community Development were significantly more likely to report the frequent use of paired and multiple frame styles than other coordinators assigned to the Program Center for 4-H and Youth, Family, and Adult Development. As noted previously, the greatest tendency was primarily a no frame style and secondarily a single frame style. However, those coordinators who did report paired or multiple frame styles were assigned to the Program Center for Agriculture, Natural Resources, and Community Development. There may be many reasons why this occurred. Coordinators in each center may inherently have a different skill set. This is plausible because the set of program responsibilities are different for each program center. However, caution must be used in making firm conclusions when the small sample $(n=33)$ was sorted into subgroups by background characteristics, some cell numbers were too small for the analyses. Additional data would need to be gathered to corroborate this finding and further explore other potential relationships.

There are many examples in the literature which examined relationships between self-rated leadership styles and demographics or other variables. These studies have shown mixed results in terms of which variables may be related to leadership styles. Self-rated leadership frame use of small campus administrators were related to institutional characteristics but not related to years 
of experience and gender (Borden, 2000). Wolf (1998) and McClellan-Holt (2000) found that years of experience did affect the use of frames. Wolf (1998) also concluded that experience affected the use of political and human resource frames. Some researchers looked at age as a variable and found that older leaders were more likely to use a multiple frame style (Chang, 2004). They were also more likely to use the political frame (Kelly, 1997; Wolf, 1998). Some studies suggested that gender is not related to leadership style or frame use (Thompson, 2000) and others found that gender was a significant variable (Chang, 2004; McClellan-Holt, 2000; Turley, 2002). Research involving leaders in business, industry, and higher education by Bolman and Deal (1991b) revealed no differences in leadership style and frame use related to gender. In conclusion, results of this study are consistent with some of the previous studies and inconsistent with some of the literature.

\section{Perspectives of Extension Service Committee Members}

Coordinators' self-rated leadership styles were compared with mean ratings from their County Extension Service Committee members. Committee members perceived coordinators to use more frames more frequently than the coordinators rated themselves. The majority of committee members reported a multiple frame style $(54.5 \%)$. The no frame style was the next most prevalent style $(21.2 \%)$, followed by the single frame style $(18.2 \%)$, and the paired frame style (6.0\%). Eight of the 33 (24\%) coordinator-committee member matched scores agreed on the leadership style; twenty-five (76\%) of the matched scores did not agree.

Different perspectives and ratings were certainly anticipated. In fact, the reason why the two parallel survey instruments were created is because any one perspective is just that - one person's point of view. Bolman and Deal recognized the validity of self-ratings is low and this is why the use of both the (self) and (other) instruments are recommended. Computing a mean 
committee member score with between two and eight scores for each coordinator adds validity to the ratings. Committee members definitely see coordinators as more skillful than the coordinators see themselves. This point is more important than the accuracy of any score. Understanding leadership skills and behaviors requires many different viewpoints, none of which are right or wrong.

Research that involved leader ratings by others provided a meaningful comparison with this study. In two studies of nursing department chairpersons, faculty perceived the chair as using the no frame style the most followed by four frame, single frame, multiple frame, and paired frame (Mosser, 2000; Small, 2002). Another study of academic chairs found that faculty rated their chairs as using a no frame style the most followed by single frame, multiple frame, and paired frame (Chang, 2004). In general, there was no clear pattern found in the literature regarding other-rated leadership styles. The results of this study are consistent with some studies and inconsistent with others. It is important to recognize that the inherent relationship between academic chairs and faculty is very different than the relationship between coordinators and committee members in this study. The committee members are considered key stakeholders, representing the communities and constituents that the coordinator serves. Additionally, the committee approves or disapproves annual personnel memoranda for placement of personnel in the county office. Thus, the relationship between a coordinator and committee members is critical to his or her continued job security.

Distinct differences were found in this study between committee member mean ratings and coordinator self-ratings of leadership styles. Despite these differences, the analysis of committee member and coordinator leadership frame scores revealed similarities. Just as coordinators preferred the human resource frame, two-thirds $(66.7 \%)$ of the committee member mean ratings 
indicated coordinators frequently use the human resource frame. Two-thirds (66.7\%) also reported frequent use of the structural frame. Over half (54.5\%) of the committee member mean scores indicated frequent use of the political frame. Slightly less (51.5\%) of the committee member mean scores reported frequent use of the symbolic frame. The frame use reported by coordinators and committee members were somewhat similar in rank order: (1) human resource and structural, (2) political, and (3) symbolic. There was no statistically significant relationship between the two sets of scores because committee member mean scores were much higher than coordinator scores.

Research Question 4 revealed only one significant relationship between leadership styles identified by coordinators and those identified by committee members. Coordinators with a selfidentified multiple frame style were significantly more likely to be viewed as multiple frame style leaders by their committee members, when compared to coordinators with no frame, single frame, or paired frame styles. There were no studies found in the literature which involved similar higher education leaders and used both versions of the Bolman and Deal instruments to compare self and other ratings. Typically, research was conducted using only one of the surveys. Therefore, self and other ratings found in this study cannot be assessed in terms of other research trends.

Research suggests that leaders may gain certain advantages when others give them high ratings. A study of academic deans revealed that those who had significantly higher political frame scores were perceived as more effective than those with lower political frame scores (Cantu, 1997). Department chairs who frequently used the symbolic frame were recognized for their use of strategic planning documents in communication and decision-making processes (Bassoppo-Moyo, 1999). In this study, coordinators did not receive high ratings in political or 
symbolic frame use in comparison with human resource and structural frames. However, committee members did give higher political and symbolic frame scores than coordinators gave themselves. This study concludes that the overall positive ratings of coordinators by committee members may result in additional positive effects. If, in the future, coordinators increased their political and symbolic frame skills, this may bring about further benefits to these leaders and to the WVUES organization.

\section{Critical Leadership Incidents}

The survey included open-ended questions to discover coordinators' critical leadership incidents and how they may relate to the leadership styles. In their own words, coordinators described personal examples of accomplishments, challenges, and specific leadership skills and behaviors. These examples followed similar themes revealed in previous research questions. In terms of frame use patterns, coordinators cited accomplishments and challenges which were human resource and structural in nature. Office relationships and supervisory authority were common themes. Budget issues and lack of funding were also common responses. Coordinators showed the tendency to use frames in the order of human resource, structural, political, and symbolic.

Many responses reflected more than one frame. Many coordinators described their personal situations and experiences by weaving several frame concepts together. Precise leadership styles were not discernible from this set of qualitative data. Responses could not be categorized into a no frame style, single frame style, paired frame style, or multiple frame style. Reponses provided more than topics to categorize into leadership frames or styles. Responses yielded a window into coordinators' leadership experiences. These experiences ranged from the positive end of the spectrum to the negative end of the spectrum. Coordinators described glowing successes as well 
as dismal, frustrating failures. Coordinator expressions were colorful and emotion filled. The very nature and purpose of qualitative inquiry is to add a deeper human dimension to the data.

Several conclusions may be drawn from the results of Research Question 5. First, the responses mirrored the leadership frame choices. Second, qualitative data exposes the personal dimension of leadership that would otherwise be missed. While the Bolman and Deal survey instrument generated numerical scores and patterns that categorized leaders into distinct types, the open-ended qualitative format provided responses that show the reason why multiple frame leadership is needed. Leaders face big challenges and need to possess a whole array of skills. Other research studies that used Bolman and Deal's leadership frames endorsed the need for a mixed method approach that included qualitative data (Chang, 2004; Borden, 2000; Mosser, 2000; Hollingsworth, 1995).

Studies have used the Bolman and Deal frame concepts in a qualitative approach. Interestingly, researchers who have conducted interviews concluded that a high proportion of leaders used multiple frames (Bensimon, 1989; Bolman \& Deal, 1999; Echols Tobe, 1999; Flaer, 1998; Flak, 1998; Harlow, 1994; Neumann, 1989; Neumann \& Bensimon, 1990; Turley, 2002). Many of these studies demonstrated that the qualitative approach seemed to result in a much higher proportion of multiple frame assessments. The political and symbolic frames emerge more than in the quantitative survey method. Several of these studies deal with college and university presidents, but their results present an interesting comparison with those found in this study. Echols Tobe (1999) found that 100\% of college presidents demonstrated a multiple frame style in interviews, compared to $67 \%$ reporting a multiple frame style as measured by the Leadership Orientations (Self) Survey scores. A study of medical school deans found that all used multiple frames with the human resource the most predominant frame and political the least 
dominant (Flaer, 1998). Turley's (2002) study of radiation therapy program directors found 44\% had a multiple frame style using the Bolman and Deal survey, while $60 \%$ were multiple frame style leaders when using qualitative data. Leader interviews about critical incidents reinforced the same frame use pattern and also suggested experienced leaders used the political frame more in describing incidents and less experienced leaders described incidents using the structural frame (Harlow, 1994). It is concluded that qualitative research including this study reveals that leaders may actually use a broader range of leadership frames than is detected in the Leadership Orientations Survey.

\section{Recommendations}

\section{Recommendations for Leadership Practices}

The results of this study have implications for leadership practices within the WVUES organization in terms of realizing its leadership capacity. To be effective across a variety of critical leadership challenges, coordinators need to possess skills in the structural, human resource, political, and symbolic leadership frames. In addition to having and using leadership skills, coordinators' effectiveness could be influenced and even enhanced by positive relationships with key stakeholders. The perceptions of key stakeholders, such as committee members, are important in helping the extension organization maintain viability at the community level.

1. The WVUES organization should embrace the leadership role of County Program Coordinators as one of importance since they carry out significant leadership responsibilities. They are the largest single group of leaders in the organization, yet they are rarely regarded as part of the leadership infrastructure. Greater acknowledgement, enhanced support, and inclusion in leadership activities may lead coordinators to readily 
identify themselves as organizational leaders. It may also diminish the reluctant attitude some coordinators may have in taking on added responsibilities without authority.

2. Although coordinators' leadership is generally recognized as important to the organization, this group of leaders does not have a clear group or team identity.

Development of a strong leadership core will require a paradigm shift to unify this team and empower them an essential element of a state leadership team.

3. A County Program Coordinator professional development program may improve leadership skills. The literature suggests the need for competency-based professional development programs, particularly for mid-level leaders. Potential strategies may include formal workshops, simulations, web-based or on-line learning modules, and mentoring. Practical, hands-on training activities that may be directly applied to the day to day work environment would be most beneficial. Training needs to be flexible, individualized according to coordinator and county needs, and fit within the time and budget constraints.

4. Additional training on the four leadership frames may be specifically focused on political and symbolic skills to help coordinators achieve a balanced, multiple frame style. This may enhance their confidence and frequent use of each leadership frame.

5. Leadership development training may benefit extension faculty at all levels, not only County Program Coordinators. A broad leadership training program may help to crosstrain faculty, prepare future County Program Coordinators, and increase the overall leadership capacity of the organization.

6. County Extension Service Committee membership is mandated in state code and new members must be approved by the President of West Virginia University. Orientation and 
ongoing training would be advantageous for WVUES and committee members to help them carry out their committee leadership responsibilities. Training could also increase their knowledge and understanding of County Program Coordinator roles and leadership expectations.

7. Results of this study need to be shared with coordinators. The major findings are essential for them to understand how they may be perceived, the differences in self and other perspectives, and the possible implications for their work to foster productive working relationships.

8. As suggested in previous studies, the survey may be a useful tool for search committees (Chang, 2004; Mosser, 2000; Small, 2002). Interview questions that delve into each of the four leadership frames may provide a broad assessment of potential employees' skill sets.

\section{Recommendations for Future Study}

This study explored a sample of leaders in one organization. Therefore, the results are limited by the scope and methodology used in the study.

1. Expand the study to include more participants. Leaders and committee members in other state extension services could be surveyed. A larger sample would enable more powerful analyses to be made and results may be generalized with greater confidence.

2. Gather additional ratings from County Program Coordinator peers, supervisors, and subordinates. This would give a broader, 360 degree perspective.

3. More in-depth study is needed on political and symbolic frame use among extension leaders. This research may reveal why leaders are less likely to use these frames often and what strategies may increase use of these underutilized frames. 
4. Further study is needed to determine exactly what factors impact leadership styles. One possibility would be to explore the variable of age. Some studies indicate that a leader's age was found to have a significant relationship with the use of certain frames (e.g. political) as well as a multiple frame style. Further analysis with County Program Coordinator age could be compared with other studies.

5. Revise and pilot test the Leadership Orientations (Other) Survey Section II so that it is less confusing for non-academic study participants.

6. A longitudinal study of County Program Coordinators would be beneficial to help demonstrate how leadership may change over time. Factors that influence leadership changes may also be revealed.

7. Further study is needed to identify underlying factors related to extension leadership styles. A study with leadership style as an independent variable may help explore such factors. Many studies have combined Bolman and Deal surveys and other established instruments such as the Cooke-Mohrman Job Satisfaction Scale, Borrevik's Organizational Climate Description Questionnaire, and Cameron's Assessment of Organizational Structures and Effectiveness. The research literature shows strong relationships between leadership style and organizational climate (Mosser, 2000), organizational effectiveness (Bedore, 1998; Bethel, 1998), work ethic (Hollingsworth, 1995), use of strategic planning documents (Bassoppo-Moyo, 1999), job stress (Russell, 2000), job satisfaction (Russell, 2000; Crist, 1999; Mathis, 1999), and faculty use of instructional technology (Chang, 2004). 
8. Additional qualitative research should be undertaken to further probe the ideas expressed by the coordinators. Interviews and focus groups may be effective approaches to gather ideas about current problems and future strategies. 


\section{Bibliography}

Altbach, P.G., Berdahl, R.O., \& Gumport, P.J. (1999). American higher education in the twentyfirst century: Social, political, and economic challenges. Baltimore: Johns Hopkins University Press.

Bass, B.M. (1981). Stogdill's handbook of leadership: A survey of theory and research. New York: The Free Press.

Bassano, L.V. (1987). Perceptions of organizational climate, job satisfaction and job performance. Dissertation Abstracts International. UMI Dissertation Services Item: 9967224

Bassoppo-Moyo, S. (1999). The relationship between department chairs' leadership frames and their usage of academic program review results. Dissertation Abstracts International. UMI Dissertation Services Item: 9933446.

Bedore, M.R. (1998). A multi-frame analysis of leadership orientation and its relationship to the leadership effectiveness and management effectiveness of human resource executives. Dissertation Abstracts International. UMI Dissertation Services Item: 9939776.

Bensimon, E. (1989). The meaning of "good presidential leadership": A frame analysis. The Review of Higher Education, 12(2) 107-123.

Bensimon, E., Neumann, A., \& Birnbaum, R. (1989). Making sense of administrative leadership: The ' $l$ ' word in higher education. (ASHE-ERIC Higher Education Report No. 1). Washington, D.C.: The George Washington University.

Bethel, C.N. (1998). A study of the relationship between presidential leadership orientation and organizational effectiveness in Bible colleges. Dissertation Abstracts International. UMI Dissertation Services Item: 9926656. 
Birnbaum, R. (1988). How colleges work: The cybernetics of academic organization and leadership. San Francisco: Jossey-Bass.

Birnbaum, R. (1989). The implicit leadership theories of college and university presidents. The Review of Higher Education 12(2), 125-136.

Bolman, L. G. (2001). Lee Bolman Web Page. [On-line]. Available from: http://www.bsbpa.umkc.edu/classes/bolman.

Bolman, L.G., \& Deal, T.E. (1984). Modern approaches to understanding and managing organizations. San Francisco: Jossey-Bass.

Bolman, L.G., \& Deal, T.E. (1991a). Images of Leadership (NCEL Occasional Paper No. 7). Nashville, TN: National Center for Educational Leadership. (ERIC Document Reproduction Service No. ED 332 345).

Bolman, L.G., \& Deal, T.E. (1991b). Leadership and management effectiveness: A multiframe, multi-sector analysis. Human Resource Management, 30(4), 509-534.

Bolman, L.G., \& Deal, T.E. (1992). Leading and managing: Effects of context, culture, and gender. Educational Administration Quarterly 28(3), 314-329.

Bolman, L.G., \& Deal, T.E. (1994). Looking for leadership: Another search party's report. Educational Administration Quarterly 30(1), 77-96.

Bolman, L.G., \& Deal, T.E. (1995). Leading with soul. San Francisco: Jossey-Bass.

Bolman, L.G., \& Deal, T.E. (1997). Reframing organizations artistry, choice, and leadership $\left(2^{\text {nd }}\right.$ ed. $)$. San Francisco: Jossey-Bass.

Bolman, L.G., \& Deal, T.E. (1999). Versatile leadership: A comparative analysis of reframing in Venezuelan managers. Paper presented at the Ibero American Academy of Management World Wide Bilingual Conference, December 9-11, 1999. 
Boone, D.A. (1988). Correlates of extension personnel performance on the Ohio Cooperative Extension Service Assessment Center. Dissertation Abstracts International. UMI Dissertation Services Item: 8824462.

Borden, M.P. (2000). Leadership orientations of area campus administrators in Florida's state university and community college systems: A frame analysis. Dissertation Abstracts International, 61(10A), 3913.

Bowditch, J.L., \& Buono, A.F. (1985). A primer on organizational behavior. New York: Wiley. Broshar, D., \& Jost, M. (1995). Understanding and changing Iowa State University Extension's management culture. Journal of Extension, 33(2).

Brown, W., Birnstihl, E.A., \& Wheeler, D.W. (1996). Leading without authority: An examination of the impact of transformational leadership cooperative extension work groups and teams. Journal of Extension, 34(5).

Cantu, D.A. (1997). The leadership frames of academic deans randomly selected and nominated as exceptionally effective at public colleges and universities. Dissertation Abstracts International. UMI Dissertation Services Item: 9724134.

Carter, R.W. (1995). Presidential administrative teams' leadership styles at public universities in Illinois. Dissertation Abstracts International. UMI Dissertation Services Item: 9540223.

Chaffee, E.E. (1989). Leadership in higher education: Variations on a theme. The Review of Higher Education, 12(2), 167-175.

Chang, T. (2004). Leadership styles of department chairs and faculty utilization of instructional technology. (Doctoral dissertation, West Virginia University, 2004).

Clark, K.E., \& Clark, M.B. (1992). Introduction. In K.E. Clark, M.B. Clark, \& D.P. Campbell 
(Eds.), Impact of leadership (pp. 131-148). Greensboro, NC: Center for Creative Leadership.

Clegg, S.R. \& Hardy, C. (1999). Studying organization theory and method. Thousand Oaks, CA: Sage.

Conger, J.A. (1999). Charismatic and transformational leadership in organizations: An insider's perspective on these developing streams of research. Leadership Quarterly 10(2), 145170.

Cooper, A.W., \& Graham, D.L. (2001). Competencies needed to be successful county agents and county supervisors. Journal of Extension, 39(1).

Cote, A.B. (1999). Leadership orientation frames of Florida elementary principals in relationship to school context and principal characteristics. Dissertation Abstracts International, 60(12A), 4257.

Cox, D.M. (1989). Managerial characteristics of county extension directors: A study of the training and preparation prerequisite for effective performance. Dissertation Abstracts International. UMI Dissertation Services Item: 8922036.

Creswell, J.W. (1994). Research design: Qualitative \& quantitative approaches. Thousand Oaks, CA: Sage.

Crist, B.E. (1999). A study of the relationship of the job satisfaction of chief academic officers of institutions of higher education and the perceived leadership style of the institution's president. Dissertation Abstracts International. UMI Dissertation Services Item: 9967224.

Davis, T.I. (1996). The ways administrators work: A study of the theoretical frames of 
leadership used by female and male secondary school principals in Pennsylvania. Dissertation Abstracts International. UMI Dissertation Services Item: 9632022.

Dever, J.T. (1997). Reconciling educational leadership and the learning organization. Community College Review, 25(2), 57-63.

Dillman, D.A. (2000). Mail and internet surveys: The tailored design method. New York: Wiley.

Durocher, E.A.. (1995). Leadership orientations of school administrators: A survey of nationally recognized school leaders. Dissertation Abstracts International. UMI Dissertation Services Item: 9620148.

Echols Tobe, D. (1999). The development of cognitive leadership frames among African American female college presidents. Dissertation Abstracts International, 60(07A), 2300.

Fiol, C.M. (1999). Charismatic leadership: Strategies for effecting social change. Leadership Quarterly, 10(3), 449-483.

Flaer, P.J. (1998). A frame analysis of the leadership styles of dental and medical school deans. Dissertation Abstracts International. UMI Dissertation Services Item: 9903257.

Flak, T.M. (1998). An inquiry into the leadership orientations of selected women school superintendents. Dissertation Abstracts International. UMI Dissertation Services Item: 9920823.

Frick, D.R. (1996). A causal-comparative study of the leadership orientation frames of superintendents and their perceptions about educational change. Dissertation Abstracts International. UMI Dissertation Services Item: 9626237.

Ganter, P.M. (1989). Organizational leadership expectations and leadership training required for effectiveness of county extension leaders in the University of Tennessee Agricultural 
Extension Service. Dissertation Abstracts International. UMI Dissertation Services Item: 9017479.

Gardner, J.W. (1990). On leadership. New York: The Free Press.

Graham, F.C. (1982). Job stress in Mississippi Cooperative Extension Service county personnel as related to age, gender, district, tenure, position and perceived leadership behavior of immediate supervisors. Dissertation Abstracts International. UMI Dissertation Services Item: 8227541.

Gunderson, G.J. (1994). How leaders lead through organizational change and transition:

Postpositivist inquiry into the beliefs, actions and reflections of leaders in the cooperative extension system. Dissertation Abstracts International. UMI Dissertation Services Item: 9505211.

Harlow, J.H. (1994). Educational leadership: A frame analysis. Dissertation Abstracts International. UMI Dissertation Services Item: 9427416.

Harrison, W.A. (1984). An analysis of the county extension director's administrative role in Michigan. Dissertation Abstracts International. UMI Dissertation Services Item: 8424429.

Haynes, B.R. (2000). Management skills of county extension administrators: Are they sufficient to do the job? Journal of Extension, 38(2).

Heimovics, R.D., Herman, R.D., \& Jurkiewicz, C.L. (1995). The political dimension of effective nonprofit leadership. Nonprofit Management and Leadership: A Quarterly Journal, 5(3), 233-248. 
Heimovics, R.D., Herman, R.D., \& Jurkiewicz Coughlin, C.L. (1993). Executive leadership and resource dependence in nonprofit organizations: A frame analysis. Public Administration Review, 53(5), 419-427.

Herzberg, F. (1966). Work and the nature of man. New York: World Publishing. Herzberg, F. (1982). The managerial choice: To be efficient and to be human. (2 ${ }^{\text {nd }}$ ed.). Salt Lake City, UT: Olympus.

Hollingsworth, C. (1995). Leadership characteristics and work ethic of Tennessee Agricultural Extension Service home economists. Dissertation Abstracts International. UMI Dissertation Services Item: 9619616.

House, R.J. (1971). A path-goal theory of leadership effectiveness. Administrative Science Quarterly, 16, 321-338.

Hoy, W.K., \& Miskel, C.G. (1996). Educational administration, theory, research, and practice. New York: McGraw-Hill.

Hunt, J.G. (1999). From where we sit: An assessment of transformational and charismatic leadership research. Leadership Quarterly, 10(3), 335-343.

Kanfer, R. (1990). Motivation theory and industrial and organizational psychology. In M.D. Dunnette, \& L.M. Hough (Eds.), Handbook of industrial and organizational psychology ( $2^{\text {nd }}$ ed., pp. 75-165). Palo Alto, CA: Consulting Psychologists Press.

Kellogg Commission on the Future of State and Land-Grant Universities. (2000). Renewing the covenant: Learning, discovery, and engagement in a new age and different world. Available from: http://www.nasulgc.org. 
Kelly, J.H. (1997). Leadership orientations of executives in business and industry and administrators in higher education. Dissertation Abstracts International. UMI Dissertation Services Item: 9841309.

Kerr, C. (1995). The uses of the university ( $4^{\text {th }}$ ed.). Cambridge, MA: Harvard University Press.

Kerr, S., \& Jermier, J.M. (1978). Substitutes for leadership: Their meaning and measurement. Organizational Behavior and Human Performance, 22, pp. 375-403.

Ladewig, H., \& Rohs, F.R. (2000). Southern extension leadership development: Leadership development for a learning organization. Journal of Extension, 38(3).

Lashway, L. (1996). The strategies of a leader. (ERIC Clearinghouse on Higher Education No. ED 406718)

Leslie, D.W., \& Fretwell, E.K., Jr. (1996). Wise moves in hard times: Creating and managing resilient colleges and universities. San Francisco: Jossey-Bass.

Locke, E.A., \& Latham, G.P. (1984). Goal setting a motivational technique that works! Englewood Cliffs, NJ: Prentice-Hall.

Mathis, S.G. (1999). The relationship of leadership frame use of departmental chairs to faculty job satisfaction as perceived by selected departmental faculty members. Dissertation Abstracts International. 60(06A),1936.

McClellan-Holt, J.E. (2000). Leadership orientations of student personnel professionals. Dissertation Abstracts International. UMI Dissertation Services Item: 9977819.

Mosser, N.R. (2000). A study of the relationship between the perceived leadership style of nursing chairpersons and the organizational climate in baccalaureate nursing programs. Dissertation Abstracts International. UMI Dissertation Services Item: AA19999952. 
Neumann, A. (1989). Strategic leadership: The changing orientations of college presidents. The Review of Higher Education, 12(2), 137-151.

Neumann, A., \& Bensimon, E.M. (1990). Constructing the presidency college presidents' images of their leadership roles: A comparative study. Journal of Higher Education, $61(6), 678-701$.

Norman, C.L. (1988). An analysis of organizational climate and training needs of the Georgia Cooperative Extension Service. Dissertation Abstracts International. UMI Dissertation Services Item: 8812091.

Patterson, T.F., Jr. (1995). TQM in extension's crystal ball. Journal of Extension, 33(2).

Patton, M.Q. (1990). Qualitative evaluation and research methods, $2^{\text {nd }}$ edition. London: Sage.

Peterson, W.L. (1987). The role of the supervisory process as perceived by extension supervisors and county agents employed by the Cooperative Extension Service. Dissertation Abstracts International. UMI Dissertation Services Item: 8724512.

Radhakrishna, R., Yoder, E.P., \& Baggett, C.D. (1994). Leadership effectiveness of county extension directors. Journal of Extension, 32(2).

Rivers, P.G. (1996). A frame analysis of principals' leadership orientations (multiframe thinking). (Doctoral dissertation, University of Central Florida, 1996). Dissertation Abstracts International. UMI Dissertation Services Item: AAG9637016.

Russell, C.A. (2000). Community college academic deans: Leadership frames and stress. Dissertation Abstracts International, 61(10A).

Sashkin, M., Rosenbach, W.E., Deal, T.E., \& Peterson, K.D. (1992). Assessing transformational leadership and its impact. In K.E. Clark, M.B. Clark, \& D.P. Campbell 
(Eds.), Impact of leadership (pp. 131-148). Greensboro, NC: Center for Creative Leadership.

Scott, D.K. (1997). An exploratory study of leadership and organizational climate/culture of NCAA and NAIA finalists for the 1995-1996 Sears Directors' Cup (athletic directors). (Doctoral dissertation, University of Northern Colorado, 1997). [On-line]. Dissertation Abstracts International. Abstract from: Dissertation Abstracts Online File: UMI Dissertation Services Item: AAG9806137.

Senge, P.M. (1996). Leading learning organizations. Training \& Development, 50(12), 36-37.

Siegrist, G. (1999). Educational leadership must move beyond management training to visionary and moral transformational leaders. Education, 120(2), 297-303.

Small, T.T. (2002). A study of the relationship between the perceived leadership style of nursing chairpersons and the organizational effectiveness of baccalaureate nursing programs. (Doctoral dissertation, West Virginia University, 2002). [On-line]. Dissertation Abstracts International. Abstract from: Dissertation Abstracts Online File: UMI Dissertation Services Item: AA13055943.

Smalley, J.M. (1985). Perceptions of nine change agent roles and related work variables by county extension agents in the Minnesota Agricultural Extension Service-1985. (Doctoral dissertation, The Louisiana State University and Agricultural and Mechanical College 1985). [On-line]. Dissertation Abstracts International. Abstract from: Dissertation Abstracts Online File: UMI Dissertation Services Item: 8610672.

Thomas, R.K. (2000). Women in leadership: An examination of transformational leadership, gender role orientation and leadership effectiveness. (Doctoral dissertation, Gonzaga 
University, 2000). [On-line]. Dissertation Abstracts International. Abstract from:

Dissertation Abstracts Online File: UMI Dissertation Services Item: 9978106.

Thompson, M.D. (2000). Gender, leadership orientation, and effectiveness: Testing the theoretical models of Bolman and Deal and Quinn. Sex Roles, 42(11/12); 969-992.

Tierney, W.G. (1989). Symbolism and presidential perceptions of leadership. The Review of Higher Education, 12(2) 153-166.

Travis, A.L. (1996). Leadership styles of senior student affairs officers: A comparison by race and gender. (Doctoral dissertation, University of South Carolina, 1996).

Turley, C.L. (2002). Radiation therapy program directors: A frame analysis of leadership in higher education. (Doctoral dissertation, The George Washington University, 2002).

United States Department of Agriculture. (1986). Basic Charter. Washington, DC: U.S. Government Printing Office.

Van Eron, A.M., \& Burke, W.W. (1992). The transformational/transactional leadership model: A study of critical components. In K.E. Clark, M.B. Clark, \& D.P. Campbell (Eds.), Impact of leadership (pp. 149-166). Greensboro, NC: Center for Creative Leadership.

Vroom, V.H., \& Jago, A.G. (1980). On the validity of the Vroom-Yetton model. In D. Katz, R.L. Kahn \& J.S. Adams (Eds.), The study of organizations (pp. 384-396). San Francisco: Jossey-Bass.

West Virginia University Extension Service. (1997). The New Framework. West Virginia University Extension Service Web Page. [On-line]. Available from: http://wvu.edu/ exten/. 
West Virginia University Extension Service. (2001). County Program Coordinator Position. West Virginia University Extension Service Web Page. [On-line]. Available from: http://wvu.edu/ exten/ .

West Virginia University Extension Service. (2004). Mission. West Virginia University Extension Service Web Page. [On-line]. Available from: http://wvu.edu/ exten/ .

West Virginia Agricultural Laws. Cooperative Extension Workers. § 19-8-1 (1915, 1990).

Whiteside, J.E. (1985). Validation of professional competencies essential to performing the administrative role of county extension director in the Georgia Cooperative Extension Service. (Doctoral dissertation, The University of Georgia, 1985). [On-line]. Dissertation Abstracts International. Abstract from: Dissertation Abstracts Online File: UMI Dissertation Services Item: 8514050.

Wolf, R.A. (1998). Campus safety directors: A leadership frame analysis. (Doctoral dissertation, University of Central Florida, 1998). [On-line]. Dissertation Abstracts International. Abstract from: Dissertation Abstracts Online File: UMI Dissertation Services Item: 9910810.

Yukl, G., \& Van Fleet, D.D. (1990). Theory and research on leadership in organizations. In Dunnette, M.D., \& Hough, L.M. (Eds.), Handbook of industrial and organizational psychology. (2 $2^{\text {nd }}$ ed., pp. 147-191) Palo Alto, CA: Consulting Psychologists Press. 
Appendices

\section{A. Permission to Use Surveys}

From: "Lee Bolman" <bolmanl@umkc.edu>

To: "Elaine Bowen" <EPBowen@mail.wvu.edu>

Date: $\quad$ 5/9/02 11:34AM

Subject: RE: Permission to Use Leadership Orientations Instruments

Dear Ms. Bowen:

In response to your request, I am pleased to write that you have the authors' permission to use the Leadership Orientations instruments in your research, subject to the conditions referenced in your memo.

Best wishes on your research.

Lee Bolman

Original Message

From: $\quad$ Elaine Bowen

Sent: $\quad$ Thursday, May 09, 2002 7:13 AM

To: bolmanl@umkc.edu

Subject: Permission to Use Leadership Orientations Instruments

Dear Dr. Bolman,

I request your permission to use the Leadership Orientations (Self) and Leadership Orientations (Other) survey instruments as part of my dissertation entitled

"Perspectives on the Leadership Styles of West Virginia University Extension Service County Program Coordinators". I am a doctoral candidate at West Virginia University in Educational Leadership Studies. I understand the conditions under which you grant permission, such as that the results of my research must be made available to you upon request. I appreciate your consideration of this request.

Thank you for inspiring my research.

Sincerely,

Elaine Bowen 


\section{Leadership Orientations (Self)}

\section{Behaviors}

This questionnaire asks you to describe your CPC leadership and management style by indicating how often each of the items below is true of you in your CPC leadership role. Please use the following scale to answer each item:

$\square$ Never $\square$ Occasionally $\square$ Sometimes $\square$ Often Always

So, you would answer 'Never' for an item that is never true of you, 'Occasionally' for one that is occasionally true, 'Sometimes' for an item that is sometimes true of you, and so on.

Be discriminating! The results will be more helpful if you think about each item and distinguish the things you really do all the time from the things you do seldom or never.

\section{Rating Scale}

Never Occasionally Sometimes Often Always

1. Think very clearly and logically.

2. Show high levels of support and concern for others.

3. Have exceptional ability to mobilize people and resources to get things done.

4. Inspire others to do their best.

5. Strongly emphasize careful planning and clear time lines.

6. Build trust through open and collaborative relationships.

7. Am a very skillful and shrewd negotiator.

8. Am highly charismatic.

9. Approach problems through logical analysis and careful thinking.

10. Show high sensitivity and concern for others' needs and feelings.

11. Am unusually persuasive and influential.

12. Am able to be an inspiration to others.

13. Develop and implement clear, logical policies and procedures.

14. Foster high levels of participation and involvement in decisions.

15. Anticipate and deal skillfully with organizational conflict

16. Am highly imaginative and creative.

\section{$\square$}


Rating Scale

Never Occasionally Sometimes Often Always

17. Approach problems with facts and logic.

18. Am consistently helpful and responsive to others.

19. Am very effective in getting support from people with influence and power.

20. Communicate a strong and challenging vision and sense of mission.

21. Set specific, measurable goals and hold people accountable for results.

22. Listen well and am unusually receptive to other people's ideas and input.

23. Am politically very sensitive and skillful.

24. See beyond current realities to generate exciting new opportunities.

25. Have extraordinary attention to detail.

26. Give personal recognition for work well done.

27. Develop alliances to build a strong base of support.

28. Generate loyalty and enthusiasm.

29. Strongly believe in clear structure and a chain of command.

30. Am a highly participative manager.

31. Succeed in the face of conflict and opposition.

32. Serve as an influential model of organizational aspirations and values.

Please turn to page 3. 


\section{Leadership Style}

This section asks you to describe your leadership style as a County Program Coordinator.

Please use the following scale to answer each item:

Most like you - _ _ _ _ _ _ _ _ _ _ _ _ - - Least like you

$4 \quad 3 \quad 2 \quad 1$

For each item, give the number " 4 " to the phrase that best describes you, "3" to the item that is next best, and on down to "l" for the item that is least like you.

1. My strongest skills are:
a. Analytic skills
b. Interpersonal skills
c. Political skills
d. Ability to excite and motivate

2. The best way to describe me is:
a. Technical expert
b. Good listener
c. Skilled negotiator
d. Inspirational leader

3. What has helped me the most to be successful is my ability to:
a. Make good decisions
b. Coach and develop people
c. Build strong alliances and a power base
d. Energize and inspire others

4. What people are most likely to notice about me is my:
a. Attention to detail
b. Concern for people
c. Ability to succeed, in the face of conflict and opposition
d. Charisma

5. My most important leadership trait is:
a. Clear, logical thinking
b. Caring and support for others
c. Toughness and aggressiveness
d. Imagination and creativity

6. I am best described as:
a. An analyst
b. A humanist
c. A politician
d. A visionary

Please turn over - only 4 more questions to go!

(C) 1990, Lee G. Bolman and Terence E. Deal, all rights reserved 


\section{Section III. Leadership Accomplishments \& Challenges}

Please describe in your own words.

1. What do you consider your most significant leadership accomplishment as a County Program Coordinator?

2. Could you describe the specific leadership skills or behaviors you used to accomplish this?

3. As a County Program Coordinator, what was the greatest challenge you have encountered?

4. Could you please describe the specific leadership skills or behaviors you used in addressing this challenge?

\section{Thank you for completing the survey!}

Please attach the completed survey file and email to: EPBowen@mail.wvu.edu

Or, you may mail to: Elaine Bowen 604 Knapp Hall P.O.Box 6031 Morgantown, WV 26506-6031 


\section{Leadership Orientations (Other)}

\section{Leader Behaviors}

This questionnaire asks you to describe the County Program Coordinator $(C P C)$ in your county, $X X X X X$, in terms of leadership and management style. You are asked to indicate how often each of the items below is true of the CPC. Please use the following scale to answer each item:

Never Occasionally Sometimes Often Always

So, you would answer 'Never' for an item that is never true of the CPC, 'Occasionally' for one that is occasionally true, 'Sometimes' for an item that is sometimes true of the CPC, and so on.

Be discriminating! The results will be more helpful if you think about each item and distinguish the things the $C P C$ really does all the time from the things they do seldom or never.

\section{Rating Scale}

Never Occasionally Sometimes Often Always

1. Thinks very clearly and logically.

2. Shows high levels of support and concern for others.

3. Shows exceptional ability to mobilize people and resources to get things done.

4. Inspires others to do their best.

5. Strongly emphasizes careful planning and clear time lines.

6. Builds trust through open and collaborative relationships.

7. Is a very skillful and shrewd negotiator.

8. Is highly charismatic.

9. Approaches problems through logical analysis and careful thinking.

10. Shows high sensitivity and concern for others' needs and feelings.

11. Is unusually persuasive and influential.

12. Is an inspiration to others.

13. Develops and implements clear, logical policies and procedures.

14. Fosters high levels of participation and involvement in decisions. 
Rating Scale

Never Occasionally Sometimes Often Always

15. Anticipates and deals skillfully with organizational conflict.

16. Is highly imaginative and creative.

17. Approaches problems with facts and logic.

18. Is consistently helpful and responsive to others.

19. Is very effective in getting support from people with influence and power.

20. Communicates a strong and challenging vision and sense of mission.

21. Sets specific, measurable goals and holds people accountable for results.

22. Listens well and is unusually receptive to other people's ideas and input.

23. Is politically very sensitive and skillful.

24. Sees beyond current realities to generate exciting new opportunities.

25. Has extraordinary attention to detail.

26. Gives personal recognition for work well done.

27. Develops alliances to build a strong base of support.

28. Generates loyalty and enthusiasm.

29. Strongly believes in clear structure and a chain of command.

30. Is a highly participative manager.

31. Succeeds in the face of conflict and opposition.

32. Serves as an influential model of organizational aspirations and values. 


\section{Leadership Style}

This section asks you to describe the leadership style of your County Program Coordinator (CPC), XXXXXX.

Please use the following scale to answer each item:

Most like them - . . . . . . . . . . . . . . Least like them

$4 \quad 3 \quad 1$

For each item, give the number " 4 " to the phrase that best describes the CPC, "3" to the item that is next best, and on down to "I" for the item that is least like the CPC.

1. The County Program Coordinator's strongest skills are:
a. Analytic skills
b. Interpersonal skills
c. Political skills
d. Ability to excite and motivate

2. The best way to describe the County Program Coordinator is:
a. Technical expert
b. Good listener
c. Skilled negotiator
d. Inspirational leader

3. What the County Program Coordinator does best is:
a. Make good decisions
b. Coach and develop people
c. Build strong alliances and a power base
d. Energize and inspire others

4. What people are most likely to notice about the County Program Coordinator is:
a. Attention to detail
b. Concern for people
c. Ability to succeed, in the face of conflict and opposition
d. Charisma

5. The County Program Coordinator's most important leadership trait is:
a. Clear, logical thinking
b. Caring and support for others
c. Toughness and aggressiveness
d. Imagination and creativity

6. The County Program Coordinator is best described as:
a. An analyst
b. A humanist
c. A politician
d. A visionary

Thank you for completing the survey!

\section{Please mail the completed survey to:}

1990, Lee G. Bolman and Terence E. Deal, all rights reserved

\section{Elaine Bowen}

P.O. Box 6031

Morgantown, WV 26506-6031 


\section{E-Mail Pre-notice Letter to County Program Coordinators}

June 2, 2003

\section{Dear County Program Coordinator,}

Your leadership role is very important to the West Virginia University Extension Service and we are interested in improving our organizational understanding of how county program coordinators use various leadership behaviors and styles. I ask for your participation in a study conducted by Elaine Bowen as part of her dissertation for an Ed.D. in Educational Leadership from West Virginia University. The purpose of the study is to examine the relationship and congruence between the leadership frame patterns of West Virginia University Extension Service county program coordinators from the perspectives of county program coordinators and County Extension Service Committee members. Not all counties will be selected for the study. If your county is selected, I encourage your participation because your unique perspective will provide valuable information for our organization.

You may soon receive the survey by e-mail from Elaine. In addition to the survey for county program coordinators, the members of the Extension Service Committees in selected counties will be mailed a survey and asked to participate. Only members with one year committee experience will receive the survey. Your encouragement for their participation is important. Thank you for your assistance and participation in the study.

Lawrence S. Cote, Ed.D.

Associate Provost for Extension and Public Service

West Virginia University 


\section{Pre-notice Letter to County Extension Service Committee Members}

June 6, 2003

Dear Extension Service Committee Member,

Your leadership role is very important to the West Virginia University Extension Service and we are interested in improving our organizational understanding of how county program coordinators use various leadership behaviors and styles. I ask for your participation in a study conducted by Elaine Bowen as part of her dissertation for an Ed.D. in Educational Leadership from West Virginia University. The purpose of the study is to examine the relationship and congruence between the leadership frame patterns of West Virginia University Extension Service county program coordinators from the perspectives of County Extension Service Committee members as well as county program coordinators themselves. I fully endorse the study and encourage your participation because your unique perspective will provide valuable information for our organization. You will soon be receiving the survey by mail from Elaine Bowen.

Please note that only members with one year committee experience will receive the survey, so there may be other members of your county committee who will not receive the survey. Thank you for your participation in the study.

Sincerely,

Lawrence S. Cote, Ed.D.

Associate Provost for Extension and Public Service

West Virginia University 


\section{E. E-Mail Cover Letter to Selected County Program Coordinators}

June 7, 2002

Dear County Program Coordinator,

I request your participation in a research study to examine the relationship and congruence between the leadership frame patterns of West Virginia University Extension Service County Program Coordinators from the perspectives of County Program Coordinators and County Extension Service Committee members. The research study is in partial fulfillment of the requirements for a doctorate in Educational Leadership from West Virginia University. I think that the results will be useful in many ways, such as in the recruitment, training, and support of County Program Coordinators.

You have been selected to receive a Leadership Orientations (Self) Survey via e-mail. This survey includes 42 items and will take about twenty minutes to complete. The survey requires no special knowledge, only your opinions. It is important that you know that in all phases of the study, data will be handled in such a way that protects the identity of each participant. Your responses and your county name will remain anonymous through reporting the data in aggregate form. Your participation is completely voluntary and refusal to participate or withdraw from the study will not affect your job status. You do not have to answer every item on the survey. I will provide you with a copy of the study results if you request it.

In addition to the survey for CPCs, the members of the Extension Service Committees in your county will be sent a similar survey and asked to participate. Only members with one year committee experience will receive the survey. Your encouragement for their participation is appreciated.

The Leadership Orientations (Self) Survey has been attached to make your response convenient. Please click onto the file attachment. Complete the survey and save the file. Then, forward the completed file via e-mail to me by June 13, 2002 at: EPBowen@mail.wvu.edu If you prefer to mail the survey to me, please send to:

Elaine Bowen

P.O. Box 6031

Morgantown, WV 26506-6031

Thank you very much for your time and assistance with this research study!

Sincerely,

Elaine Bowen, Ed.D. Candidate

Doctoral Program in Educational Leadership

West Virginia University 


\section{F. Cover Letter to Selected County Extension Service Committee Members}

June 11, 2003

\section{Dear XXXXXX,}

I request your participation in a research study on leadership and the West Virginia University Extension Service. The research study examines the leadership frame patterns of West Virginia University Extension Service County Program Coordinators from the perspectives of County Program Coordinators and County Extension Service Committee members. The County Program Coordinator in your county is XXXXXX. The research study is in partial fulfillment of the requirements for a doctorate in Educational Leadership from West Virginia University. I think that the results will be useful to the organization in many ways, such as in the recruitment, training, and support of county extension leaders.

Every member with at least one year of experience on the Extension Service Committee will receive a Leadership Orientations (Other) Survey. This survey includes 38 items and will take about twenty minutes to complete. The survey requires no special knowledge, only your opinions. It is important that you know that in all phases of the study, your responses and your county name will remain anonymous. Your participation is completely voluntary and refusal to participate or withdraw from the study will not affect your status on the committee. You do not have to answer every item on the survey. I will provide you with a copy of the study results if you request it.

The Leadership Orientations (Other) Survey is enclosed. Please return the survey in the enclosed stamped envelope by June 16, 2003 to:

Elaine Bowen

P.O. Box 6031

Morgantown, WV 26506-6031

I appreciate your time and assistance with this research study - thank you!

Sincerely,

Elaine Bowen, Ed.D. Candidate

Doctoral Program in Educational Leadership West Virginia University

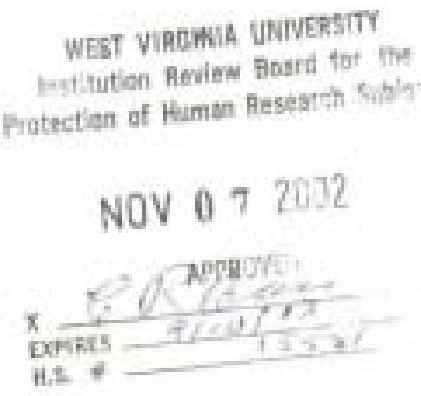




\section{G. Institutional Review Board Approval}

\section{West Virginia University Office of Research Compliance}

DATE: November 7, 2002

This research will be monitored for re-approval annually. APPROVAL PERIOD: September 11, 2002 to September 10, 2003

NOTICE OF APPROVAL FOR PROTOCOL: HS \#15581

TO: $\quad$ Elaine Bowen

TITLE: Leadership Orientations of West Virginia University Extension Service County Program Coordinators

AGENCY: $\quad \mathrm{N} / \mathrm{A}$

The Institutional Review Board for the Protection of Human Research subjects (IRB) has approved the project described above. Approval was based on the descriptive material and procedures you submitted for review. Should any changes in your protocol/consent for be necessary, prior approval must be obtained from the IRB.

According to the Code of Federal Regulations, Section 312.32, investigators are required to notify the FDA and the study sponsor of any adverse experience associated with the use of an investigational drug that is serious and unexpected. A serious adverse experience is considered any event that is fatal or life-threatening, is permanently disabling, requires inpatient hospitalization, or is a congenital anomaly, cancer, or overdose. An unexpected adverse experience is an event that is not identified in nature, severity, or frequency in the current investigator brochure. Any experience reportable to FDA and the sponsor must also be reported immediately to the IRB.

A consent form* $\underline{X}$ is not required of each subject. An assent form__ is $X$ is _ is not required of each subject. A recruitment ad has__ has not $\underline{X}$ been approved.

Phone: $304-293-7073$

Fax: $304-293-7435$
Chestnut Ridge Research Building 886 Chestnut Ridge Road P0 Box 6845 Morgantown, WV 26506-6845 
Date: November 7, 2002

Page -2-

Bowen

HS \#15581

Only copies of the consent and/or assent form with the IRB's approval stamp may be used with human subject research. It is the responsibility of the investigator to submit a revised consent form for the IRB's approval should funding be obtained. This stamped consent form must then be used for subjects enrolled. A copy of each subject's signed Consent/Assent Form must be retained by the investigator and accessible to federal regulatory authorities for at least three years after the study is completed.

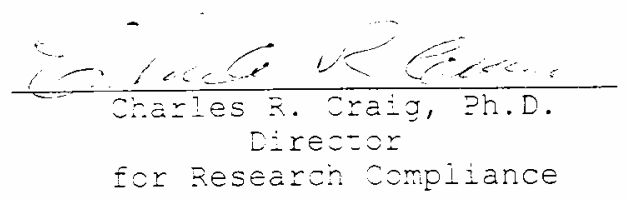

$\mathrm{CRW} / \mathrm{baw}$ 


\section{Curriculum Vitae}

Elaine Bowen has twenty five years of experience as an extension educator at county, regional, and state levels, with a primary focus on community health education. She is currently in the position of Extension Specialist -Health Promotion with the West Virginia University Extension Service. Previous to this, she served in several administrative positions and worked closely with County Program Coordinators and County Extension Service Committees.

Her academic background includes a Bachelor's of Science degree in Home Economics Education and Extension from Virginia Tech and a Master's of Science degree in Family Resources from West Virginia University. She is certified in Family and Consumer Sciences with the American Association of Family and Consumer Sciences and maintains licensure with the West Virginia Board of Licensed Dietitians. 